
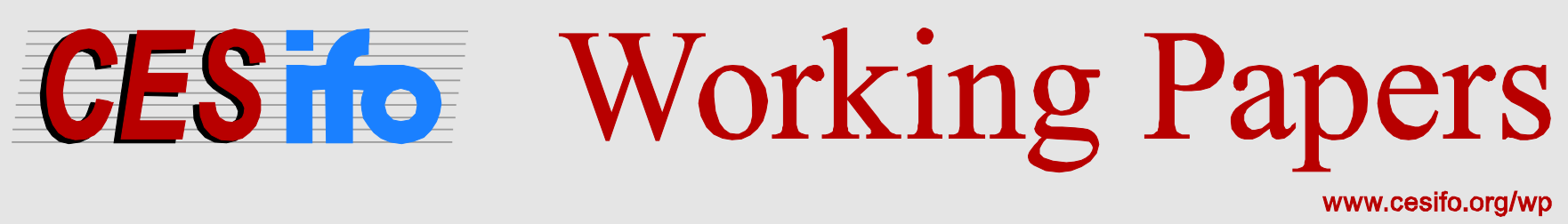

\title{
On the Allocation of Time - A Quantitative Analysis of the U.S. and France
}

\author{
Georg Duernecker \\ Berthold Herrendorf
}

\author{
CESIFO WORKING PAPER NO. 5475 \\ CATEgory 6: Fiscal Policy, MaCROECONOMICS AND GROWTH \\ August 2015
}

An electronic version of the paper may be downloaded

- from the SSRN website:

- from the RePEc website:

- from the CESifo website:

wWw.SSRN.com

www.RePEc.org

www.CESifo-group.org/wp 


\title{
On the Allocation of Time - A Quantitative Analysis of the U.S. and France
}

\begin{abstract}
We study the allocation of time in the U.S. and in Europe during 1960-2010. We find that market hours decreased and leisure increased most in France and least in the U.S. Contrary to what standard theory predicts, home hours changed comparatively little. We show that the growth model with home production can account for the patterns in France and the U.S. if we feed in taxes and labor productivities. To obtain this result it is crucial to measure the labor productivity of home production in a comparable way in both countries, instead of calibrating these productivities like the literature does.
\end{abstract}

JEL-Code: E100, J400.

Keywords: home production, labor productivity, leisure, time allocation.

\author{
Georg Duernecker \\ Department of Economics \\ University of Mannheim \\ Germany - 68131 Mannheim \\ duernecker@uni-mannheim.de
}

\author{
Berthold Herrendorf \\ Department of Economics \\ W.P. Carey School of Business \\ Arizona State University \\ USA - Tempe, AZ 85287-9801 \\ berthold.herrendorf@asu.edu
}

First version: October 1, 2012

This version: April 22, 2015

For helpful comments and suggestions, we would like to thank Alexander Bick, Lei Fang, Charles Gottlieb, John Hassler, Dirk Krueger, Cara McDaniel, Franck Portier, Valerie Ramey, Richard Rogerson, Todd Schoellman, Ákos Valentinyi, Gustavo Ventura and the audiences at Arizona State University, Cardiff Business School, the Canadian Macro Study Group, the Central Banks of Chile and Finland, the CEPR Summer Symposium in International Macroeconomics, the Federal Reserve Bank of St. Louis, the IIES in Stockholm, the Ifo Conference on Macroeconomics and Survey Data, the Meetings of the Society of Economics Dynamics, the NBER Summer Institute (Macro Perspectives), the Nordic Summer Symposium in Macroeconomics, the North American Meetings of the Econometric Society, Rice, the Stockholm School of Economics, Stony Brook, and the Universities of Adelaide and Mannheim. Herrendorf thanks the Spanish Ministry of Education for research support (Grant ECO2012-31358) and the University of Mannheim for its hospitality during a sabbatical in 2012 when this project originated. Duernecker thanks the Institute for International Economic Studies for its hospitality during 2014. All errors are our own. 


\section{Introduction}

Starting with the seminal paper of Becker (1965), many scholars have studied what determines how people allocate their time among different activities. A prominent example is Prescott (2004), who argued that differences in income taxes are an important reason for why Americans work more in the market than Continental Europeans. Prescott's contribution stimulated a growing literature in quantitative macroeconomics that assesses how public policy affects the allocation of time among market work, home work, and leisure. ${ }^{1}$ A consensus view is emerging in this literature that hours worked differ as basic micro theory predicts: in developed countries in which taxes increased, people reduced their hours worked in the market and increased their hours worked at home. ${ }^{2}$ However, to the best of our knowledge there is not much hard evidence corroborating this view. Indeed, the most detailed evidence exists for the U.S. where Aguiar and Hurst (2007b), Ramey (2009), and Ramey and Francis (2009) documented long time series for both leisure and home hours. Outside of the U.S., Gimenez-Nadal and Sevilla-Sanz (2012) documented facts about leisure for several countries from the 1970s to the 2000s, but long time series for home hours are missing. ${ }^{3}$

In this paper we shed more light on how people allocate their time. We come up with consistent estimates of the average hours that a working-age person allocates to market work, home work and leisure in the U.S. and the large European countries France, Germany, and the UK during 1960-2010. The stylized fact that emerges from our analysis is that in all four countries, changes in market hours are mostly offset by changes in leisure while hours devoted to home production change little in comparison. ${ }^{4}$ Since this stylized fact is at odds with the prediction of standard micro theory, we want to understand why people allocate their time in the way they do. To make progress in this regard, we narrow our focus to the two countries that are at the opposite ends of the spectrum, namely the U.S. and France. Whereas the time allocation in the U.S. changed relatively little, the French decreased market hours and increased leisure by the largest amounts. We start to study these two countries in 1970, because from then on we have all French data that are required for the rest of our analysis. We stop in 2005 because our focus is on secular trends and not on the Great Recession. ${ }^{5}$

\footnotetext{
${ }^{1}$ See for example Greenwood et al. (2005), Rogerson (2007), Rogerson (2008), Ngai and Pissarides (2008,2011), Ohanian et al. (2008), Olovsson (2009), Rendall (2010), McDaniel (2011), Guner et al (2012a,b), Ngai and Petrongolo (2013), Ragan (2013), Bick (2014) and Bick and Fuchs-Schuendeln (2014).

${ }^{2}$ Scandinavia is the notable exception where people work more than theory predicts. Rogerson (2007), Olovsson (2009), and Ragan (2013) argued that this is due to the nature of public expenditures and transfers in Scandinavia.

${ }^{3}$ Juster and Stafford (1991), Freeman and Schettkat (2001), Burda et al. (2008) and Ragan (2013) provide evidence from individual cross sections.

${ }^{4}$ In independent work that came to our attention after the first draft of this paper was completed, Fang and McDaniel (2014) document similar facts. In contrast to us, however, they do not provide an explanation for them.

${ }^{5}$ Aguiar et al. (2013) study the allocation of time during the Great Recession. Later on, we will also investigate the out-of-sample performance of our model during 2005-2010.
} 
In order to understand the economic forces behind the time allocations in the U.S. and France during 1970-2005, we view them through the lens of the growth model with home production. ${ }^{6}$ Our model has the following key features: there is subsistence consumption that implies that the income elasticity of consumption is smaller than one and the income elasticity of leisure is larger than one; consumption is produced both in the market and at home whereas investment is produced only in the market; capital and labor are used in both market production and home production. To discipline our model, we require that it be consistent with the observed labor productivities of market work and home work and with the observed relative prices of investments in the stocks of market and home capital. Except for the labor productivity of home production, we can use off-the-shelf values for these statistics.

Obtaining numbers for the labor productivity of home production is challenging because the value added produced at home is not traded in the market. The literature, therefore, calibrates the real labor productivity of home production. In contrast, we impute it both for the U.S. and France following the income approach that the BEA uses for its satellite accounts, which many experts of NIPA have endorsed. ${ }^{7}$ According to this approach, the value added of home production equals the sum of hours worked at home and capital used at home, each multiplied by an appropriate rental rate. Real labor productivity of home production then is obtained as the ratio of the imputed value added divided by a price deflator and the hours worked at home.

Two insights emerge from imputing the real labor productivity of home production in this way. First, it has almost stagnated in the U.S. during 1970-2005, which is similar to what most calibration exercises infer; see for example Rogerson (2008) or McDaniel (2011). Second, in France labor productivity at home started at a lower level than in the U.S. from which it has grown to catch up with the U.S. level. This is different from what typical calibration exercises assume. We will see below that this difference is the key reason why leisure, and not home hours, has soaked up most of the reduction in market hours in France.

We calibrate our model to match the allocation of time in the U.S. in 1970 and 2005 as well as the paths of the labor productivities in the market and at home and the relative prices of market and home investments. The model does well at replicating the secular trends of the U.S. time allocation during 1970-2005. We also find that although we only target the time allocation in 1970 and in 2005, the model also captures most of what happened also during 1965-1970 and 2005-2010. Turning to France, we impose upon our model the actual French data series for taxes, labor productivities in the market and at home, and the relative prices of investments in France. We find that the otherwise unchanged model accounts well for the time allocation

\footnotetext{
${ }^{6}$ Benhabib et al. (1991) and Greenwood and Hercowitz (1991) were the first papers that developed versions of the growth model with home production.

${ }^{7}$ Juster and Stafford (1991) offer a detailed justification for using this approach in the context of home production. Bridgman (2013) implemented a similar exercise for the U.S. during the last century. To the best of our knowledge we are the first to provide comparable numbers for France. In a companion paper, Bridgman et al. (2014), we impute the value added of home production for a broad set of OECD countries.
} 
in France. In particular, it replicates that the time allocated to leisure increased by roughly the same hours as the time allocated to market work decreased, and that the changes in leisure and market hours in France were large compared to the U.S. We provide economic intuition for our results by conducting counterfactual exercises and by deriving analytical solutions for a static version of our model.

The key reason for why our model replicates the French allocation of non-market time is that it captures how the increases in the effective income taxes interact with the increases in labor productivity of home production in France. If we had instead made the usual assumption that French labor productivity at home stagnated as it did in the U.S., then we would have obtained the counterfactual prediction of the literature that the decrease in market hours was accompanied by an increase in home hours of similar size. Our findings have two important implications. First, home hours increase with labor income taxes only if the relative labor productivities of market versus home production remain unchanged. Whereas this is typically assumed in the literature, we find evidence that suggests otherwise. Second, although there are many potential issues with using the income approach to impute the value added produced at home, the resulting numbers for home labor productivity reconcile the evidence on home hours with a standard version of the growth model. We show that the standard calibration procedure that is usually followed in the literature does not deliver numbers that do this.

Our findings are related to the thesis of Freeman and Schettkat (2005) that the U.S. experienced a marketization of consumption during which people substituted market-produced consumption for home-produced consumption, whereas this happened to a much lesser extent, if at all in Continental Europe. Given our imputed numbers for real value added produced at home, we can ask how the composition of consumption changed over time. We find that Americans strongly increased the ratio of market- to home-produced consumption whereas the French decreased it. In other words, the marketization of consumption happened in the U.S. but not in France. The marketization hypothesis does not come through as clearly when one looks at how these two countries allocated their time. The reason, of course, is that the relative labor productivities of market to home production behaved differently in the U.S. and France, implying that hours differences do not translate into the same consumption differences in both countries.

The rest of the paper is organized as follows. In the next section, we carefully document the facts about home production in the U.S. and the large European countries. In the subsequent section, we lay out our environment and characterize the equilibrium. Section 4 connects our model with the U.S. data. Section 5 contains the results for France, the intuition for our results, and the results from several counterfactual exercises. Section 6 concludes. An appendix contains technical details and the documentation of our data work. 


\section{What the Data Say about Home Production}

\subsection{Evidence on the Allocation of Time}

\subsubsection{Evidence for the U.S., France, Germany, and the UK}

We start by reporting the facts about the allocation of time in the U.S. and in France, Germany, and the UK. We choose these countries because they are the large rich European countries and we have enough data for them to estimate time series of hours worked and leisure during the last fifty years. While the U.S. facts are well known from the work of Ramey (2009), Ramey and Francis (2009) and Aguiar and Hurst (2007b), the evidence outside of the U.S. is more spotty and comes from either single cross sections or from a few cross sections that are fairly close together in time. Freeman and Schettkat (2001) and Ragan (2013) are examples of the former and Burda et al. (2008) and Juster and Stafford (1991) of the latter. A notable exception is Gimenez-Nadal and Sevilla-Sanz (2012) who documented facts about leisure in seven OECD countries during the 1970s, 1980s, 1990s, and the 2000s. However, they do not report much evidence about home production time. Moreover, there are some issues with their work that make it hard to interpret. Specifically, they included school/classes and study time in market work, which is in contrast to the standard way of defining market work. Moreover, although they tried to exclude retirees and students from their samples, the Multinational Time Use Study (MTUS) data for France in 1965 and 1975 actually do not have the information about the retirement/student status that is required for the exclusion. We conjecture that therefore their early series for France include retirees and students. This is likely to be important because retirees and students presumably work more at home than employed people of the same age. Thus, leaving them in the early sample while excluding them from the later sample is likely to imply a downward bias in the resulting series of home hours and an upward bias in the resulting series of market hours.

Our data sources for the time allocation are the time use surveys that were standardized by MTUS. Table 10 in Appendix A.1 lists the dates and number of participants of each time use survey. Although time use surveys are not available as frequently as one would want, the ones that are available are typically large and representative. We deal with the fact that surveys are not conducted every year by interpolating and extrapolating the data points that we have, taking into account the available information about changes in the demographic composition of the working-age population and in market hours worked from the Groningen Growth and Development Centre (GGDC henceforth). Appendix A.2 explains the details. Note that since our interpolation and extrapolation take into account that market hours fluctuate over time, the estimated non-market hours too fluctuate between two observations.

We define market work as paid work in the market and at home plus travel to and from work. We use a concept of home work that is close to that of Ramey (2009), implying that we include 

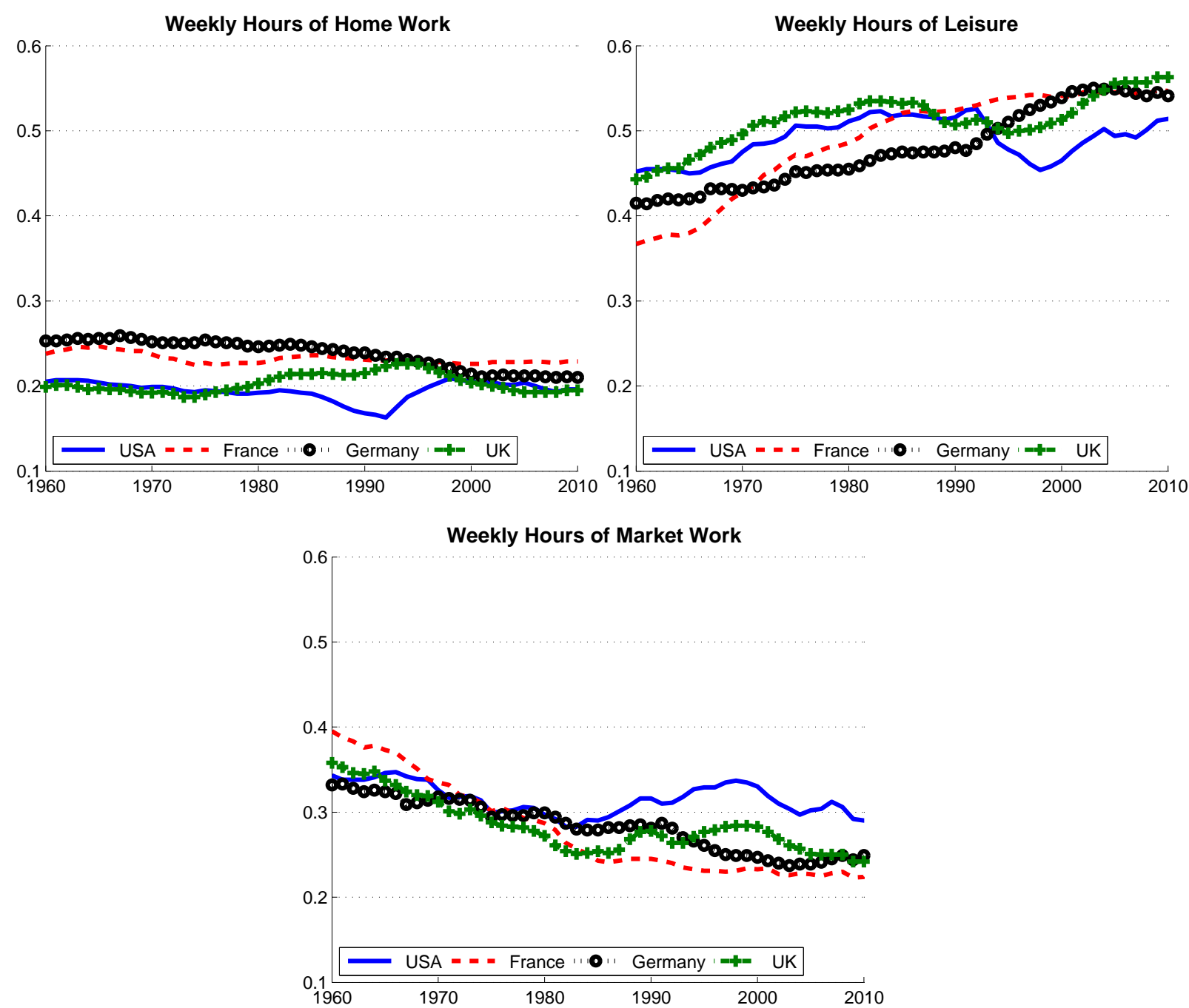

Figure 1: Allocation of Time 1960-2012 (fractions of total available time)

gardening, shopping, and childcare in home production. We define leisure as the remaining disposable time where disposable time is total time after sleep, personal care, and education. A list of the categories included in market work, home work and leisure can be found in Table 11 of Appendix A.1.

Figures 1 show the resulting time patterns for the U.S., France, Germany, and the U.K. All numbers are in percent of an average person's disposable weekly time. We can see that hours worked at home behaved similarly in all countries: they declined somewhat and then converged to similar levels towards the end of the sample. In contrast, hours allocated to leisure increased strongly in all three European countries but increased only mildly in the U.S. Market hours showed the opposite trends than leisure. It is worth pointing out that the strong decline in French market hours happened long before the statutory work week of 35 hours was introduced in February 2000. 
Given the existing work on home production in the U.S., it is natural to compare our estimates of home hours for the U.S. with the existing ones. Table 1 reports the series for home hours in Aguiar and Hurst (2007b), Ramey (2009), and our study. ${ }^{8}$ Perhaps the most obvious difference between the three studies is that the level of hours differ. This is due to several subtle differences among them. To begin with, the age groups are different: in order to ensure comparability with the literature on cross-country labor supply, we focus on the working-age population 15-64 years old whereas the other two studies start later at 18 and 21 years, respectively. ${ }^{9}$ Moreover, Ramey and Aguiar-Hurst used the AHTUS data whereas we use MTUS data. MTUS has the advantage that it allows us to compare time use patterns across countries, but MTUS has fewer time use categories than AHTUS. Table 12 in Appendix A.1 lists in detail how this difference between the data sources is reflected in the time use categories of the three studies.

Irrespective of the differences among the three studies, they agree that home hours fall until 1992 and then go up to the previous level again, and that as a result there is no pronounced trend between 1975 and 2003. Given that we study the period 1970-2005 in our quantitative analysis, the slight differences before 1975 are of minor concern. We add three observations. First, if we used the same age group as Aguiar-Hurst, then we would get that home hours declined more strongly by 1.2 hours during the first ten years; compare row 4 of Table 1 . This is twice as much as we estimate for the age group 15-64. Second, different from Aguiar-Hurst, our numbers include students and retirees and do not control for demographic change. Instead, we follow Ramey and compute the time allocation of the average individual in the economy in a given year. One implication of this point is that one should not expect our series for home hours to be exactly equal to that of Aguiar-Hurst. Third, in order to ensure comparability with the data from the first half of the 20th century, Ramey needs to exclude a number of activities from home production that are arguably part of home production and that we therefore include in it. Using additional information that MTUS offers for the U.S. but not for France, we can replicate Ramey's steps closely. Appendix A.3 shows that then we virtually get the same results as Ramey, which is reassuring because we followed her methodology.

\subsubsection{More Evidence for the U.S. and France}

In what follows, we will narrow our focus to the U.S. and France. The reason for leaving out Germany is that the unification introduced serious data issues at the beginning of the 1990s. The reason for leaving out the UK is that a number of statistics which we require later in our quantitative analysis are not available for the U.K. We plan to analyze Germany and the UK in

\footnotetext{
${ }^{8}$ The reported numbers of Aguiar-Hurst include childcare in home production.

${ }^{9}$ The 1965 and 1975 time use survey for the USA did not sample individuals younger than 19 and 18, respectively. To compute the time allocation for the age group 15-19, we use information from the UK time use survey for the same (or a similar) year and the relative time allocation between age groups.
} 
Table 1: Average weekly hours of home work in the U.S.

\begin{tabular}{|c|c|c|c|c|c|c|c|c|}
\hline & & Age & Source & 1965 & 1975 & 1985 & 1992 & 2003 \\
\hline 1 & Ramey & $18-64$ & AHTUS & 26.5 & 22.5 & 21.3 & 22.0 & 23.5 \\
\hline 2 & Aguiar-Hurst & $21-65$ & AHTUS & 25.8 & 23.3 & 24.6 & 21.5 & 23.8 \\
\hline 3 & Duernecker-Herrendorf & $15-64$ & MTUS & 20.6 & 20.0 & 19.2 & 16.4 & 20.3 \\
\hline 4 & Duernecker-Herrendorf & $21-65$ & MTUS & 22.6 & 21.4 & 20.4 & 17.6 & 21.8 \\
\hline
\end{tabular}

future work. We start analyzing the U.S. and France in 1970 because some data required for other aspects of our analysis are not available before 1970. We stop in 2005 because we want to avoid the Great Recession.

While for the U.S. there are microdata from many time use surveys, for France we only have microdata from time use surveys from 1965, 1970, and 1998. This implies that extrapolation and interpolation play an important role in obtaining the French series; see Appendix A.2 for the details of how we extrapolate and interpolate. In order to make sure that our findings are not driven by the details of that procedure, we compare them with the results from two additional French time use surveys that were collected in 1985 and in 2010. We did not use these surveys in the estimation because INSEE makes them available only in rather aggregate form (the 1985 survey is available in book form in the INSEE library whereas the 2010 survey is available online). Nonetheless, we find that our estimated numbers for 1985 and 2010 are reassuringly close to those implied by the numbers published by INSEE. The results are available upon request.

Table 2 reports the allocation of time in the U.S. and France during 1970-2005. Part (i) of Table 2 reports the numbers for the Ramey classification that we use for our baseline analysis. 32.6 in the table means that in 1970 a working-age American on average allocated 32.6 percent of his disposable time to working in the market. The table implies the following key facts about the allocation time among home work, leisure, and market work during 1970-2005: in 1970, people in the U.S. and France devoted more hours to work at home and in the market than to leisure; in 2005, people in the U.S. devoted more hours to work while people in France devoted more hours to leisure; between 1970 and 2005, changes in market hours and leisure roughly offset each other and hours devoted to home production did not change much in comparison. ${ }^{10}$

There is a debate in the literature about several choices that Ramey made. It turns out, however, that these choices are not driving our the key features of the time allocation in the U.S. and France. To begin with, Aguiar and Hurst (2007b) argued that it is instructive to separate the changes in hours that result from changes of individual behavior from those resulting from changes in the demographic composition of the population. While the baseline part of Table 2

\footnotetext{
${ }^{10}$ Ramey (2009) discovered a related fact about the first half of the last century: Americans hardly reduced the home hours they provided themselves but reduced the home hours that they hired.
} 
Table 2: Hours per working-age population (as shares of available time)

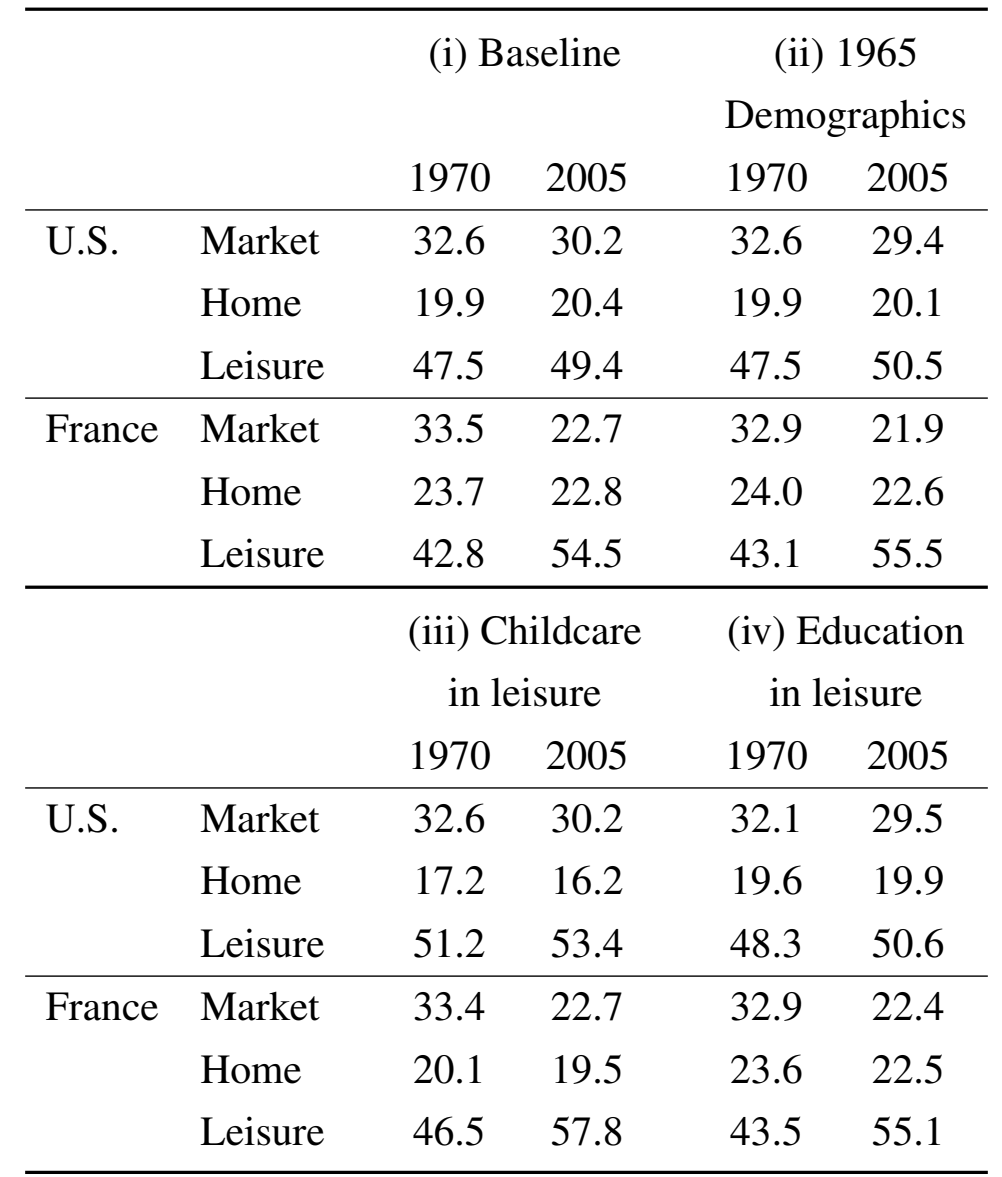

Sources: MTUS

reports the average hours with the actual demographic composition of the population, part (ii) reports the average hours if the demographic composition is kept constant at the 1965 values. ${ }^{11}$ We can see that while the levels change, the qualitative patterns described above are robust. ${ }^{12}$ Aguiar and Hurst (2007b) also argued that it may be more appropriate to include child care in leisure instead of in home production. Part (iii) of Table 2 reports average hours if we include child care in leisure. We can see that while the levels change, the qualitative patterns described above again do not. In particular, it is still the case that changes in market hours are roughly offset by opposing changes in leisure while home hours change much less.

Another potential robustness issue with our classification is that we have excluded education from the disposable time. In contrast, some authors include education as part of disposable time and classify it as leisure; see for example Rogerson (2008). Although it seems plausible to us

\footnotetext{
${ }^{11}$ In this exercise, we use the 1965 demographics instead of the 1970 demographics because a time use survey was collected for 1965 but not for 1970.

${ }^{12}$ Since the data about the statistics other than the time allocation, to which we will connect our model below, are generated in economies with changing demographics, we find it preferable to work with the time allocations for changing demographics.
} 
that education has a leisure component, we do not feel comfortable with classifying it entirely as leisure. Be that as it may, part (iv) of the table reports the numbers if we include education both in the total available time and in leisure. Again, the qualitative patterns described above are robust although including education in total disposable time changes the shares of market work in total disposable time.

A last natural question to ask at this point is why we calculate market hours from MTUS instead of using the off-the-shelf numbers from the OECD or the GGDC. A first reason for using MTUS is that we want our estimates for market hours, home hours and leisure to be based on the same data source. In addition, there is an issue with the cross-country comparability of the numbers from the standard data sources. In particular, on its website the OECD explicitly warns the reader that ".. the data are intended for comparisons of trends over time; they are unsuitable for comparisons of the level of average annual hours of work for a given year, because of differences in their sources". ${ }^{13}$ One important reason for the lack of comparability is that the data sources of the OECD are not of the same type: depending on the country the data sources either are labor force surveys, employer surveys, or NIPA employment (which presumably is based on labor force and/or employer surveys). Another reason for the lack of cross-country comparability is that the national labor force surveys treat holidays in different ways. Bick et al. (2014) show that this can lead to considerable biases in the measures of hours worked.
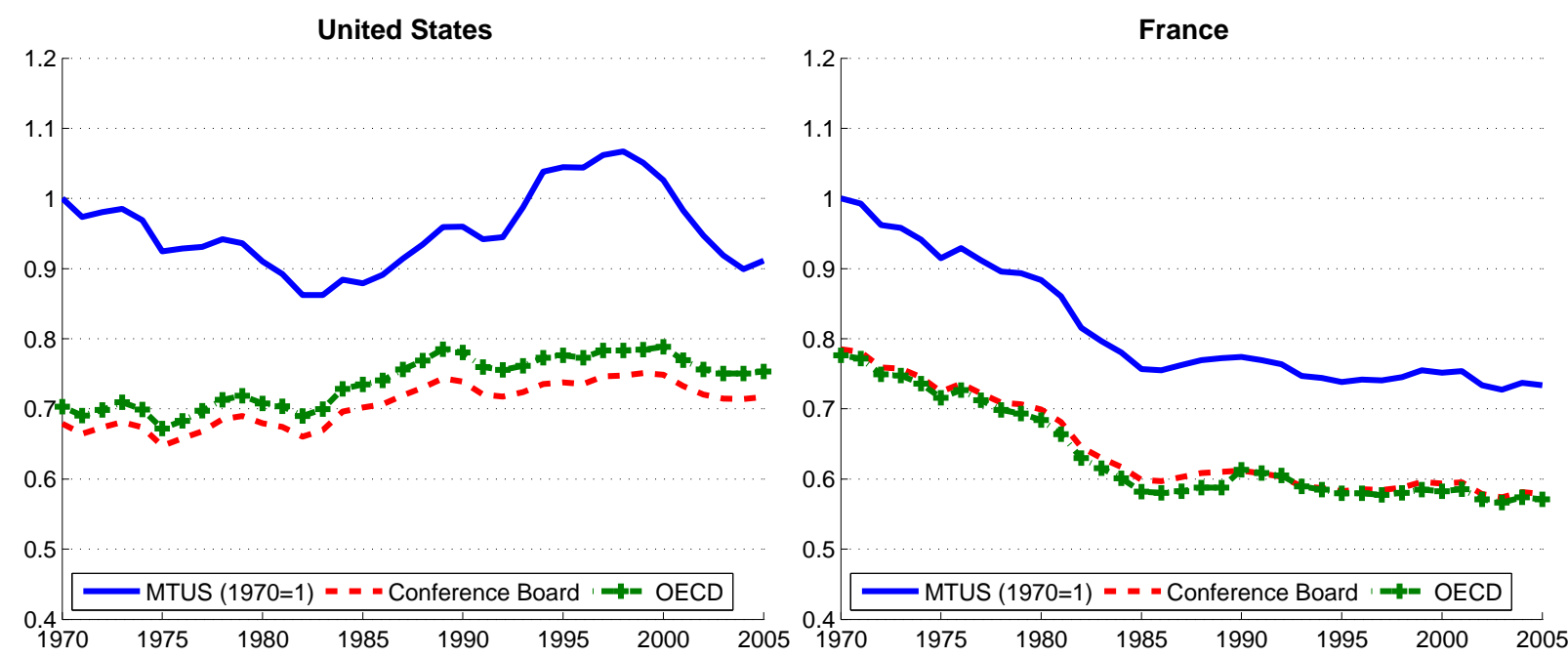

Figure 2: Market Hours 1970-2005 from different Data Sources (hours are divided by the MTUS 1970 hours)

Despite the discussion in the previous paragraph, it is of interest to compare separately for each country the time series patterns of hours worked from MTUS with those from the OECD

\footnotetext{
${ }^{13}$ This statement appears when one clicks the info button next to the title of http://stats.oecd.org/Index.aspx?DataSetCode=ANHRS.
} 
and the Conference Board. Figure 2 shows that the levels of our series are larger. This is not surprising because our measure of market hours is broader in that it includes commuting time which labor force surveys tend to leave out. Other than that, the qualitative patterns are similar, that is, hours worked in the market decline in France compared to the U.S. We should add that for the U.S. the MTUS estimates imply that market hours have declined somewhat whereas the OECD and GGDC estimates imply that they have increased somewhat. We leave it to future research to investigate the reason for this discrepancy among the different data sources.

\subsection{Evidence on the Value Added of Home Production in the U.S. and France}

The goal of this subsection is to provide a measure of the value added of home production in the U.S. and France. Since it is not traded in the market, the value added of home production is not part of NIPA. ${ }^{14}$ We impute the value added of home production following the methodology underlying the BEA's Satellite Account for Household Production. This methodology is based on the income approach of calculating value added and combines information about the production factors used in home production with rental prices for comparable production factors in the market. Specifically, value added of home production equals the sum of capital and labor used at home, each multiplied with an appropriate rental price. Kendrick (1979), Landefeld et al. (2009) and Bridgman (2013) offer detailed descriptions of this methodology and Schreyer and Diewert (2014) provide a theoretical justification for it. Our contribution here is to apply this methodology to our definition of home production and to come up with comparable estimates for the value added produced at home in both the U.S. and France.

We are aware that imputing the value added of home production is subject to potential problems. In particular, it is not immediately clear what rental rates to use for labor and capital used in home production. Nonetheless, as we will see below, the numbers for the labor productivity of home production that we impute naturally reconcile the stylized facts about the time allocations in the U.S. and France with a calibrated version of the growth model with home production. In contrast, the numbers that are obtained from standard calibration procedures fail to achieve this. This gives us confidence in the results of our imputation.

We define capital used for home production as the stock of consumer durables. We view this as a first step and acknowledge that there are other sensible choices. For example, papers which study business cycles like Greenwood and Hercowitz (1991) and Fisher (2007) included residential housing as part of the capital used in home production. In contrast, Ramey (2009) focused on the substitutability between capital and labor in home production and defined home

\footnotetext{
${ }^{14} \mathrm{An}$ exception to this statement is the imputed value added for owner-occupied housing, which is included in GDP.
} 
capital more narrowly as household appliances. ${ }^{15}$ We choose not to include residential housing, because NIPA includes imputed rents of owner-occupied housing in GDP and it is convenient to use the off-the-shelf numbers for GDP. Moreover, the ratio of residential housing to GDP remained fairly constant during our period of study, implying that leaving it out of measured home value added has a level effect only. We choose to include all consumer durables, and not just household appliances, in capital used for home production because many capital goods that are used in household production are part of consumer durables but not of household appliances. Examples include equipment for gardening, tools for maintenance, cars etc. Looking ahead, we will find that capital used in home production plays a quantitatively small role for our question. This suggests that although in other contexts consumer durables may be too broad a measure of home capital, using this measure does not drive our results here.

To calculate the stock of capital used for home production, we obtain investment as the sum of the final expenditure on consumer durables in constant prices from the OECD and then use the perpetual inventory method. We convert capital in constant prices into capital in current prices by using the price index of investment in consumer durables in the current period. Appendix A.4 contains the details. We follow Bridgman (2013) and use the ten-year rates of return on government bonds plus the depreciation rate as the rental price for home capital. Note that this way of proceeding does not include in value added the valuation gains or losses that result from changes in the relative prices of consumer durables, which, as we shall see, were large during our period of study. The reason for this is that NIPA does not count valuation gains or losses as part of value added.

We impute the value added generated by hours worked at home by valuing them at the average hourly compensation of workers in the private-households sub-sector, which is reported in NIPA. To appreciate what that entails, it may be useful to recall the NAICS definition of this sub-sector: "Industries in the Private Households subsector include private households that engage in employing workers on or about the premises in activities primarily concerned with the operation of the household. These private households may employ individuals, such as cooks, maids, and butlers, and outside workers, such as gardeners, caretakers, and other maintenance workers." To calculate real labor productivity of home production, we translate nominal value added into constant-price, constant-PPP value added by using the OECD price indexes for expenditure on close market substitutes to household consumption. ${ }^{16}$

An alternative to using the compensation of workers in the private-households would be to use the average market wage as the rental price of hours worked at home. This might seem more appealing at first sight because it captures the opportunity costs of working at home in-

\footnotetext{
${ }^{15}$ We have also explored what happens if we define capital used for home production as the stock of appliances. Our results below do not change much. The results are available upon request.

${ }^{16}$ The available price indexes refer to final expenditure whereas our imputed home production is value added. Using price indexes for final expenditure for value added categories works better the smaller the share of intermediate inputs in final expenditure are.
} 


\begin{tabular}{lrrrr}
\hline & \multicolumn{2}{c}{ U.S. } & \multicolumn{2}{c}{ France } \\
& 1970 & 2005 & 1970 & 2005 \\
\hline Panel (i): Labor in the private households subsector & & & \\
Hours (millions) & 2,273 & 1,643 & 520 & 452 \\
\% of aggregate hours & 1.4 & 0.7 & 1.2 & 1.2 \\
Employment (thousands) & 2,281 & 1,313 & 137 & 225 \\
\% of aggregate employment & 2.6 & 0.9 & 0.6 & 0.9 \\
\hline Panel (ii): Average hourly wages by sector & in current \$ & in current $€$ \\
Total economy & 4.3 & 29.5 & 2.0 & 26.3 \\
Private-households sector & 2.0 & 9.4 & 1.4 & 13.1 \\
Minimum wage & 2.0 & 5.0 & 1.0 & 9.0 \\
\hline
\end{tabular}

Sources: OECD; EU KLEMS

stead of working in the market. Nonetheless, it is not appropriate to use the opportunity cost approach here, because it would imply that the productivity of working at home is determined by a person's productivity of working in the market. This would mean, for example, that $\mathrm{PhD}$ economists have a higher productivity when working at home than professional home workers, which is implausible [Schreyer and Diewert (2014)]. Moreover, estimating a life-cycle model with home production, House et al. (2008) find that for each dollar women earned in the market, on average they gave up only 25 cents worth of home production. This evidence suggests that the appropriate rental price is indeed the average wages of professional household workers which are considerably lower than the average market wages of all workers; see Panel (ii) of Table 3.

There are several other potential concerns with using the average hourly compensation of professional household workers as the rental price of home hours. To begin with, one may wonder how large this subsector is and whether our results are driven by small samples. Panel (i) of Table 3 shows that the household sector commands between half one and two-and-a-half percent of total employment. For comparison, employment in U.S. agriculture has been in the same ballpark in recent years. Second, one might suspect that the wages of French household workers are driven by the fairly high minimum wages in France. Panel (ii) of Table 3 shows that, except in the U.S. in 1970, the average wages of household workers were much larger than the minimum wage. In particular, at the end of our sample, the average wage in the privatehouseholds subsector exceeded the minimum wage considerably. A third potential concern is that the composition of human capital in the private-households sector may have changed, for 
example, because low-educated immigrants play an increasingly important role in that sector in the U.S.. Since we use wages per worker instead of wages per efficiency unit, we do not take such changes into account. This is not likely to be of first-order importance though, as most workers in the private-households sector have rather low skills to begin with. One way to see this is to compare the average wage in the private-household sector with the economy-wide average wage. Panel (ii) of Table 3 shows that the average household worker made less than half of the average hourly wage in 2005 .

Table 4 reports the results for the value added of home production. Since the absolute numbers do not mean much, we report the value added of home production in terms of two different current-price ratios: the first row divides it by GDP and the second row divides it by market-produced final consumption. We can see that in 1970 the ratios of home value added relative to GDP in the U.S. and France were identical and the ratios of home value added relative to market-produced consumption were similar. Subsequently, the U.S. experienced a strong decrease of relative home value added whereas France experienced a strong increase. In the language of Freeman and Schettkat (2005), the U.S. experienced a marketization of consumption whereas France experienced the opposite.

Table 4: Facts about Home Production

\begin{tabular}{lccccc}
\hline & \multicolumn{2}{c}{ U.S. } & \multicolumn{2}{c}{ France } \\
& 1970 & 2005 & 1970 & 2005 \\
\hline & & & & \\
& 0.32 & 0.20 & 0.32 & 0.48 \\
Home value added divided by GDP & 0.41 & 0.25 & 0.44 & 0.60 \\
Home - over market-produced consumption & 12.3 & 12.6 & 6.2 & 15.6 \\
Labor productivity, level & \multicolumn{2}{c}{0.1} & \multicolumn{2}{c}{2.6} \\
Labor productivity, average growth in \% & 1.04 & 1.55 & 0.67 & 0.53 \\
Capital-output ratio & \multicolumn{3}{c}{0} \\
\hline
\end{tabular}

Sources: MTUS, OECD, own calculations

\subsection{Evidence on the Labor Productivity of Home Production in the U.S. and France}

We are now in the position to obtain estimates of the labor productivity of home production, that is, the real value added of home production divided by hours worked. Given that we have calculated the capital stock of home production, we also report the capital-output ratio in current prices (where output refers to value added). Rows 3-5 of Table 4 list the results. Two key facts emerge: labor productivity in the U.S. has hardly grown; labor productivity in France 
started at a much lower level than in the U.S., grew at an average rate of $2.6 \%$, eventually caught up with the U.S. value, then even overtook the U.S. value. That labor productivity at home has hardly grown in the U.S. since 1970 is similar to what Bridgman (2013) found, although he used a different concept of home capital that includes part of housing and infrastructure. It is also similar to what usual calibrations of home productivity deliver. That labor productivity in France grew strongly to eventually catch up with the U.S. level is different from what is typically assumed in the literature, which postulates that the ratio of the labor productivities in the market and at home showed the same behavior in the two countries; see for example Rogerson (2008) or McDaniel (2011). We will see in subsection 5.4 below that taking into account the differences in the patterns of home labor productivity is critical for understanding the reasons behind the difference in patterns of the time allocations between the U.S. and France.

We also find that the capital-output ratio of home production has consistently been larger in the U.S. than in France. Moreover, the capital-output ratio of home production grew in the U.S. whereas it fell somewhat in France. To put the numbers into perspective, note that a typical estimate for the capital-to-output ratio in the market is around three, so home capital-to-output ratios around 0.5 are fairly small, suggesting that home production is fairly labor intensive.

\section{Model}

In this section, we build a version of the growth model with endogenous labor supply and home production. An implication of employing the growth model is that we will work with a standin household which captures what happens at the aggregate level but remains silent about what happens at the disaggregate level at the intensive and extensive margins, for men and women, in different age groups etc. We think that while these margins are important to understand why aggregate labor supply changes, a natural first step is to investigate how far we can push the aggregate model to account for the aggregate facts.

\subsection{Environment}

The stand-in household is endowed with one unit of time and positive amounts of the initial capital stocks for market and home production, $K_{m}(0)$ and $K_{h}(0)$. Households derive utility from market- and home-produced consumption, $C_{m}$ and $C_{h}$, and leisure, $L$. The period-utility function is given by:

$$
\begin{aligned}
U(C, L) & =\alpha_{u} \log (C-\bar{C})+\left(1-\alpha_{u}\right) \log (L) \\
C & =\left[\alpha_{c} C_{m}^{\sigma_{c}}+\left(1-\alpha_{c}\right) C_{h}^{\sigma_{c}}\right]^{\frac{1}{\sigma_{c}}}
\end{aligned}
$$


where $\alpha_{u}, \alpha_{c} \in(0,1)$ are relative weights, $C$ is a composite consumption good, $\bar{C}$ can be thought of as a subsistence level of consumption, $L$ is leisure, and $\sigma_{c} \in(-\infty, 1)$ determines the elasticity of substitution between market-produced and home-produced consumption (with $\sigma_{c}=0$ being the Cobb-Douglas case).

Except for the subsistence term $\bar{C}$, the above utility function is the same as that in Prescott (2004), which is commonly used in the business cycle literature. The presence of $\bar{C}$ implies that preferences are non-homothetic in that the income elasticity of leisure is larger than one. This features will be essential for matching the fact that leisure has increased in both the U.S. and France since 1970. In related work, Restuccia and Vandenbroucke (2013) and Restuccia and Vandenbroucke (2014) found that subsistence consumption is important for accounting for the long run trends of market work, leisure and educational attainment.

The technology for producing market output $Y_{m}$ is represented by a Cobb-Douglas production function:

$$
Y_{m}=\left(K_{m}\right)^{\alpha_{m}}\left(A_{m} H_{m}\right)^{1-\alpha_{m}}
$$

$K_{m}$ and $H_{m}$ are capital and hours worked in the market, $A_{m}$ is labor-augmenting technical progress, and $\alpha_{m}$ is the capital-share parameter. The technology for producing home output $Y_{h}$ is represented by a CES production function:

$$
Y_{h}=\left[\alpha_{h}\left(K_{h}\right)^{\sigma_{h}}+\left(1-\alpha_{h}\right)\left(A_{h} H_{h}\right)^{\sigma_{h}}\right]^{\frac{1}{\sigma_{h}}}
$$

$K_{h}$ and $H_{h}$ denote capital and hours allocated to home production, $A_{h}$ is labor-augmenting technological progress, $\alpha_{h}$ is the capital-share parameter, and $\sigma_{h}$ determines the elasticity of substitution between home capital and home hours. We do not a priori restrict that elasticity but calibrate it so as to match key features of home production.

Turning now to the feasibility constraints, we assume that market output may be used for market consumption, $C_{m}$ and for investment into market and home capital, $X_{m}$ and $X_{h}$. Consumption and both investments are non-negative. We also assume that the marginal rates of transformation are governed by the exogenous variables $B_{m}$ and $B_{h}$ as follows:

$$
C_{m}(t)+\frac{X_{m}(t)}{B_{m}(t)}+\frac{X_{h}(t)}{B_{h}(t)}=Y_{m}(t)
$$

A larger value of $B$ implies that less consumption has to be given up for obtaining one unit of $X$. Below we calibrate the $B$ 's so as to match the relative prices of investment in market and home capital to market consumption. 
The household faces the following additional feasibility constraints:

$$
\begin{aligned}
1 & =H_{m}(t)+H_{h}(t)+L(t) \\
C_{h}(t) & =Y_{h}(t) \\
K_{m}(t+1) & =\left(1-\delta_{m}\right) K_{m}(t)+X_{m}(t) \\
K_{h}(t+1) & =\left(1-\delta_{h}\right) K_{h}(t)+X_{h}(t)
\end{aligned}
$$

The first constraint specifies that the amounts of time allocated to market production, home production, and leisure must add up to the total time endowment of one. The second constraint specifies that home-produced consumption equals home-produced output. The last two constraints describe the accumulation of market and home capital where $\delta_{m}, \delta_{h} \in(0,1)$ denote the depreciation rates on market and home capital. Underlying these equations is the assumption that capital is sector specific, that is, it can only be used in the sector in which it is installed. Since investment is restricted to be non-negative, (6)-(7) imply the additional constraints that next period's capital stock cannot be smaller than this period's capital stock after depreciation:

$$
\begin{aligned}
K_{m}(t+1) & \geq\left(1-\delta_{m}\right) K_{m}(t) \\
K_{h}(t+1) & \geq\left(1-\delta_{h}\right) K_{h}(t)
\end{aligned}
$$

Since in our applications, all capital stocks will be non-decreasing, these constraints will not bind.

\subsection{Equilibrium}

Choosing market consumption as the numeraire, the household's budget constraint is given as: ${ }^{17}$

$$
\left(1+\tau_{c m}\right)\left(C_{m}+p_{h} X_{h}\right)+\left(1+\tau_{x m}\right) p_{m} X_{m}=\left(1-\tau_{h m}\right) w H_{m}+\left(1-\tau_{k m}\right) r K_{m}+\mathcal{T}
$$

where $p_{h}$ and $p_{m}$ are the relative prices of investment for home and market capital, $w$ and $r$ denote the wage and interest rate in terms of market consumption, $\tau_{c m}, \tau_{x m}, \tau_{h m}$, and $\tau_{k m}$ denote the tax rates on consumption and investment for home capital, on investment for market capital, on labor income, and on capital income, and $\mathcal{T}$ is a lump-sum rebate of the resulting tax revenues. Note that it will be important for our results that we assume that the tax revenues are rebated, instead of consumed by the government. The reason, of course, is that with rebated tax revenues, taxes imply a substitution effect but not an income effect. Note that investment

\footnotetext{
${ }^{17}$ Note that we abstract from the fact that many countries have specific rules according to which accounting depreciation is deductible from capital-income taxes. The reason for not taking this into account is that the capital-income tax rates from McDaniel, which we will use below, abstract from depreciation allowance and just calculate the capital-income tax rate as capital income tax paid divided by capital income.
} 
in home capital is taxed at the same tax rate as market consumption because it is composed of durable consumption goods and consumption taxes do not distinguish between durable and non-durable consumption goods. ${ }^{18}$ Dividing the budget constraint by consumption taxes gives:

$$
C_{m}+p_{h} X_{h}+\left(1+\tau_{x}\right) p_{m} X_{m}=\left(1-\tau_{w}\right) w H_{m}+\left(1-\tau_{r}\right) r K_{m}+T
$$

where the effective tax rates are given as:

$$
\begin{aligned}
\tau_{x} & \equiv \frac{\tau_{x m}-\tau_{c m}}{1+\tau_{c m}} \\
\tau_{w} & \equiv \frac{\tau_{h m}+\tau_{c m}}{1+\tau_{c m}} \\
\tau_{r} & \equiv \frac{\tau_{k m}+\tau_{c m}}{1+\tau_{c m}}
\end{aligned}
$$

Putting the different ingredients together, we obtain the household problem:

$$
\max \sum_{t=0}^{\infty} \beta^{t}\left[\alpha_{u} \log (C(t)-\bar{C})+\left(1-\alpha_{u}\right) \log (L(t))\right] \quad \text { s.t. } \quad(2)-(10) \quad \forall t
$$

Appendix B contains the first-order conditions for an interior solution to this problem. From now on, we proceed under the assumption that the (8)-(9) do not bind, solve for the equilibrium, and then verify that indeed (8)-(9) do not bind.

Assuming that individuals have perfect foresight about the path of future taxes, the definition of competitive equilibrium is as follows:

Definition. A competitive equilibrium are sequences of effective tax rates $\left\{\tau_{x}(t), \tau_{w}(t), \tau_{r}(t)\right\}$, prices $\left\{p_{h}(t), p_{m}(t), w(t), r(t)\right\}$, allocations $\left\{H_{m}(t), H_{h}(t), L(t)\right\},\left\{K_{m}(t+1), K_{h}(t+1)\right\},\left\{X_{m}(t), X_{h}(t)\right.$, $\left.C_{m}(t), C_{h}(t)\right\}$ such that

- taking prices, wages, interest rates, effective tax rates and the initial capital stocks as given, $\left\{H_{m}(t), H_{h}(t), L(t), K_{m}(t+1), K_{h}(t+1), X_{m}(t), X_{h}(t), C_{m}(t), C_{h}(t)\right\}$ solve the household problem

- taking prices and wages as given, $H_{m}(t), K_{m}(t)$ maximize profits

- markets clear.

Eliminating the multipliers, the first-order conditions to the household problem imply 4 consolidated conditions that have obvious interpretations. In writing them, we highlight the tax

\footnotetext{
${ }^{18} \mathrm{~A}$ broader definition of home capital would include residential housing. We include residential capital in market capital here because we think that the key margin of substitution between home capital and labor refers to consumer durables (e.g., washing machines) versus labor. See Greenwood and Hercowitz (1991) for a different treatment that includes residential housing in home capital.
} 
distortions in boldface. First, the optimal allocation of time between leisure and market work equalizes the marginal utilities of leisure and market work:

$$
\frac{1-\alpha_{u}}{L(t)}=\frac{\alpha_{u} \alpha_{c}}{C(t)-\bar{C}}\left[\frac{C(t)}{C_{m}(t)}\right]^{1-\sigma_{c}}\left[\mathbf{1}-\boldsymbol{\tau}_{w}(\boldsymbol{t})\right] w(t)
$$

The first-order conditions shows that the marginal utility of market work is distorted by the income tax $\tau_{w}(t)$. Second, the optimal allocation of time between home work and market work equalizes the marginal utilities of home work and market work:

$$
\frac{1-\alpha_{c}}{C_{h}(t)^{\sigma_{h}-\sigma_{c}}}\left(1-\alpha_{h}\right) A_{h}(t)^{\sigma_{h}} \frac{1}{H_{h}(t)^{1-\sigma_{h}}}=\frac{\alpha_{c}}{C_{m}(t)^{1-\sigma_{c}}}\left[\mathbf{1}-\boldsymbol{\tau}_{w}(\boldsymbol{t})\right] w(t)
$$

Again, the marginal utility of market work is distorted by the income tax $\tau_{w}(t)$. Third, the optimal allocation of market capital satisfies the following Euler equation:

$$
\begin{aligned}
& {\left[\mathbf{1}+\boldsymbol{\tau}_{x}(\boldsymbol{t})\right] \frac{C(t)^{1-\sigma_{c}}}{C(t)-\bar{C}} C_{m}(t)^{\sigma_{c}-1} p_{m}(t)=} \\
& \quad \beta \frac{C(t+1)^{1-\sigma_{c}}}{C(t+1)-\bar{C}} C_{m}(t+1)^{\sigma_{c}-1}\left\{\left[\mathbf{1}-\boldsymbol{\tau}_{r}(\boldsymbol{t}+\mathbf{1})\right] r(t+1)+\left[\mathbf{1}+\boldsymbol{\tau}_{x}(\boldsymbol{t}+\mathbf{1})\right]\left(1-\delta_{m}\right) p_{m}(t+1)\right\}
\end{aligned}
$$

This Euler equation is distorted by the investment taxes today and tomorrow and the capitalincome tax tomorrow. Fourth, the optimal allocation of home capital satisfies the following Euler equation:

$$
\begin{aligned}
& \frac{C(t)^{1-\sigma_{c}}}{C(t)-\bar{C}} \alpha_{c} C_{m}(t)^{\sigma_{c}-1} p_{h}(t)= \\
& \quad \beta \frac{C(t+1)^{1-\sigma_{c}}}{C(t+1)-\bar{C}}\left\{\left(1-\alpha_{c}\right) C_{h}(t+1)^{\sigma_{c}-\sigma_{h}} \alpha_{h} K_{h}(t+1)^{\sigma_{h}-1}+\alpha_{c} C_{m}(t+1)^{\sigma_{c}-1}\left(1-\delta_{h}\right) p_{h}(t+1)\right\}
\end{aligned}
$$

This Euler equation is not distorted by taxes because the tax on investment in household capital cancels with the tax on market consumption and no other taxes affect home production.

In each period, we have 14 endogenous variables: $p_{h}(t), p_{m}(t), w(t), r(t), H_{m}(t), H_{h}(t), L(t)$, $K_{m}(t+1), K_{h}(t+1), X_{m}(t), X_{h}(t), C(t), C_{m}(t), C_{h}(t)$. To determine these, we have the four conditions (11)-(14) from above. In addition, there are the two first-order conditions from the problem of the representative firm:

$$
\begin{aligned}
r(t) & =\alpha_{m} \frac{Y_{m}(t)}{K_{m}(t)} \\
w(t) & =\left(1-\alpha_{m}\right) \frac{Y_{m}(t)}{H_{m}(t)}
\end{aligned}
$$


Lastly, there are eight feasibility constraints:

$$
\begin{aligned}
& p_{m}(t)=\frac{1}{B_{m}(t)}, \quad p_{h}(t)=\frac{1}{B_{h}(t)} \\
& K_{m}(t+1)=\left(1-\delta_{m}\right) K_{m}(t)+X_{m}(t), \quad K_{h}(t+1)=\left(1-\delta_{h}\right) K_{h}(t)+X_{h}(t) \\
& 1=H_{m}(t)+H_{h}(t)+L(t), \quad C(t)=\left[\alpha_{c} C_{m}(t)^{\sigma_{c}}+\left(1-\alpha_{c}\right) C_{h}(t)^{\sigma_{c}}\right]^{1 / \sigma_{c}} \\
& C_{m}(t)+\frac{X_{m}(t)}{B_{m}(t)}+\frac{X_{h}(t)}{B_{h}(t)}=K_{m}(t)^{\alpha_{m}}\left[A_{m}(t) H_{m}(t)\right]^{1-\alpha_{m}} \\
& C_{h}(t)=\left[\alpha_{h} K_{h}(t)^{\sigma_{h}}+\left(1-\alpha_{h}\right)\left[A_{h}(t) H_{h}(t)\right]^{\sigma_{h}}\right]^{1 / \sigma_{h}}
\end{aligned}
$$

\section{Connecting the Model with the U.S. Data}

We now calibrate the model to the U.S. economy. Units are such that

$$
A_{m}(1970)=A_{h}(1970)=B_{m}(1970)=B_{h}(1970)=1
$$

We use the information provided on McDaniel's webpage to calculate effective tax rates for $t=1970, \ldots, 2005 .{ }^{19}$ The following parameters are chosen to obtain reasonable values for the corresponding data targets: $\beta=0.96$, which gives an average real rate of return on capital after taxes and depreciation of $4.8 \% ; \delta_{m}=0.05$ and $\delta_{h}=0.19$, which are the NIPA depreciation rates of market capital and consumer durables; $\alpha_{m}=0.37$, which is the standard capital share; $B_{m}(t)$ and $B_{h}(t)$ for $t=1971, \ldots, 2005$ so as to match the relative prices of investments in capital and consumer durables from the OECD. ${ }^{20}$

This leaves us with six parameters and the series for technological change to calibrate: the three relative weights $\alpha_{u}, \alpha_{c}, \alpha_{h}$; the two elasticity parameters $\sigma_{c}, \sigma_{h}$; the subsistence term $\bar{C}$; $A_{m}(t)$ and $A_{h}(t)$. We calibrate them jointly to hit six data targets and the annual time series for market and home labor productivity. The target are: U.S. hours worked in the market and at home for $t=1970$ and 2005 from MTUS; U.S. share of home capital investment in market output, $p_{h}(t) X_{h}(t) / Y_{m}(t)$, for $t=1970$ and 2005 from the OECD; the annual growth of U.S. labor productivity of market production and home production for $t=1971, \ldots, 2005$ from the OECD and our own calculations.

Since we have a subsistence term in the utility function, we cannot impose balanced growth on our equilibrium path. We therefore add the initial and terminal capital-output ratios in market and home production (measured in current prices) as targets to pin down the initial and final capital stocks: $p_{m}(t) K_{m}(t) / Y_{m}(t)$ for $t=1970$ and 2005 (from the BEA); $p_{h}(t) K_{h}(t) / Y_{h}(t)$

\footnotetext{
${ }^{19}$ See http://www.caramcdaniel.com/researchpapers and McDaniel (2007) for a additional details.

${ }^{20}$ There are different concept of what constitutes capital used in home production. The broadest concept includes residential housing. The narrowest concept includes only household appliances. Consumer durables is between these two concepts. We use it here because comparable data are available from NIPA for both the U.S. and France.
} 
for $t=1970$ and 2005 (from the BEA and own calculations). An alternative to our way of proceeding would be to recognize that given sustained growth the subsistence terms becomes negligible at time goes to infinity and the model converges to a balanced growth path. Instead of imposing the terminal capital-output ratios in market and home production from the data, we could therefore impose that at some date far in future the model reaches a balanced growth path; see for example McDaniel (2011). At first sight, this way of proceeding appears to impose less information from the data. We emphasize, however, that one would need to take a stand on the growth rates of technical change between the last period for which we have data and the future period when the balanced growth path is presumably reached. McDaniel (2011) assumed that technological progress grows at some constant rate. Since this is ad hoc, we prefer to impose the terminal conditions from actual data. Having said this, we should add that if the alternative way of proceeding replicates the paths that the two capital stocks take during the time period for which we have data, then the two ways of proceeding give the same results for the allocation of time. In other words, choosing between them is purely a matter of taste and not essential for what we are after here.

Table 5: Average Annual Growth Rates in the U.S. (in \%)

\begin{tabular}{cccc}
\hline & & Data & Model \\
\hline Labor productivity of & & & \\
market production & $\Delta Y_{m} / H_{m}$ & 1.69 & 1.69 \\
home production & $\Delta Y_{h} / H_{h}$ & 0.07 & 0.07 \\
Technological change in & & & \\
market production & $\Delta A_{m}$ & & 1.03 \\
home production & $\Delta A_{h}$ & & -0.32 \\
market investment & $\Delta B_{m}$ & & 1.01 \\
home investment & $\Delta B_{h}$ & & 3.07 \\
\hline
\end{tabular}

Table 5 shows the technological progress implied by our calibration and that we hit the targets for labor productivity exactly. Interestingly, although we have negative labor-augmenting technical change at home, we can match the small but positive labor productivity growth at home. The reason why these seemingly contradictory statements are true at the same time is because of massive investments in consumer durables, which were spurred by the large fall in the relative price of home capital that our model maps into large technical progress of $3.07 \%$ per year. One interpretation of negative labor-augmenting technical change at home is that it reflects a deterioration of the human capital used at home. There are several possible reasons for this. To begin with, people may just know less about home economics than they used to. This is consistent with the fact that home economics is no longer taught at schools. A second 
possible reason is related to the fact that during our period of investigation women have entered the labor force in large numbers. If the women who left the home for the market have higher than average human capital relevant for home work, then selection may explain why average human capital used in home production has decreased. An additional effect of women entering the labor force is that a larger part of homework is now done by men. If men have less human capital relevant for home work than women, then the average human capital used in home production has decreased yet further. Our model with a stand-in household and without heterogenous skills will interpret these selection and composition effects as negative technological change occurring at home. We leave it to future research to pursue these issues more seriously.

Table 6: Targets of the Joint Calibration to the U.S. Economy

\begin{tabular}{lccccc}
\hline & & \multicolumn{2}{c}{ Data } & \multicolumn{2}{c}{ Model } \\
& & 1970 & 2005 & 1970 & 2005 \\
\hline Market hours & $H_{m}$ & 32.6 & 30.2 & 32.6 & 30.2 \\
Home hours & $H_{h}$ & 19.9 & 20.4 & 19.9 & 20.4 \\
Share of consumer durables in GDP & $p_{h} X_{h} / Y_{m}$ & 0.11 & 0.10 & 0.11 & 0.10 \\
Capital-output ratio in the market & $p_{m} K_{m} / Y_{m}$ & 2.99 & 3.14 & 2.99 & 3.14 \\
Capital-output ratio at home & $p_{h} K_{h} / Y_{h}$ & 1.04 & 1.55 & 1.04 & 1.55 \\
\hline
\end{tabular}

Table 6 shows that our model hits the six joint targets exactly. Note that since the shares of market work, home work, and leisure add up to one, we hit the shares for leisure exactly too, and so we do not report leisure as an independent target. A skeptical reader might suspect that the model hits the shares exactly because we cherry picked our period of investigation. To preempt this suspicion, we have also investigated how our model performs out of sample during 1965-1970 and 2005-2010. Table 7 shows that the results are encouraging: our model captures very well what happened to the time allocation during 1965-1970, that market hours declined during 2005-2010, and that leisure increased during 2005-2010; but the increase in leisure is somewhat too small; the previous two points imply that our model misses that home hours fell somewhat during 2005-2010. Overall our model does a good job at capturing that during 1965-2010, market home and hours did not change much while the sizeable decrease in market hours was offset by an increase in leisure of similar size, which is what it was designed for. To fine tune the short-run performance of our model during the Great Recession, we suspect that it will be necessary to add features such as adjustment costs or learning by doing. We leave investigating this to future research.

The calibrated parameter values are in Table 8. We emphasize the following features of our calibration: home capital and home labor come out as complements; there is a positive subsistence level of consumption; market-produced and home-produced consumption come out as 
Table 7: Out-of-sample Performance of our Model for the U.S.

\begin{tabular}{lcccccccc}
\hline & \multicolumn{4}{c}{ Data } & \multicolumn{4}{c}{ Model } \\
& 1965 & 1970 & 2005 & 2010 & 1965 & 1970 & 2005 & 2010 \\
\hline Market hours & 34.6 & 32.6 & 30.2 & 29.0 & 34.5 & 32.6 & 30.2 & 29.1 \\
Home hours & 20.4 & 19.9 & 20.4 & 19.6 & 20.1 & 19.9 & 20.4 & 20.6 \\
Leisure & 45.0 & 47.5 & 49.4 & 51.4 & 45.4 & 47.5 & 49.4 & 50.3 \\
\hline
\end{tabular}

complements. Some remarks are useful to put the calibrated parameter values into perspective. First, the value 0.08 for the relative weight on home capital is fairly low. This is likely to be due to the fact that we have defined home capital as consumer durables, which does not include residential housing. Second, to get a sense of the importance of the subsistence term, we express it as a share of total consumption: in the U.S., $\bar{C}$ amounted to $17 \%$ of total consumption in 1970 and $11 \%$ in 2005 . Third, the finding that capital and labor are complements in home production is consistent with the estimate of Ramey (2009); defining household capital more narrowly as household appliances, she obtained an elasticity of substitution of 0.8 between appliances and labor in home production.

Table 8: Calibrated Parameter Values

\begin{tabular}{lcc}
\hline Weight on consumption & $\alpha_{u}$ & 0.54 \\
Weight on market-produced consumption & $\alpha_{c}$ & 0.79 \\
Weight on home capital & $\alpha_{h}$ & 0.08 \\
Non-homotheticity term & $\bar{C}$ & 0.10 \\
Elasticity between home capital and home labor & $1 /\left(1-\sigma_{h}\right)$ & 0.88 \\
Elasticity between market and home-produced consumption & $1 /\left(1-\sigma_{c}\right)$ & 0.76 \\
\hline
\end{tabular}

Our calibrated value of 0.76 for the elasticity substitution between home consumption and market consumption is much lower than the values that are typically used in the literature. For example, the closely related paper by Rogerson (2008) chose an elasticity of 1.82 , implying that home consumption and market consumption are substitutes. It is important to realize that the elasticity is not a deep parameter that is invariant across environments, but that it depends on the environment. In particular, his elasticity governs the substitutability with market-produced services whereas our elasticity governs the substitutability market-produced consumption. Since market-produced consumption contains both the services and the goods that are consumed, it has many components that are not substitutable with home produced consumption. Therefore, our elasticity is expected be lower than his elasticity. To establish this point more formally, we 
abstract from capital for a moment so that the production functions become linear in labor:

$$
C_{j}=A_{j} H_{j}, \quad j \in\{m, h\}
$$

The first-order condition (12) for the optimal allocation of time between home work and market work then simplifies to:

$$
\frac{H_{m}}{H_{h}}=\left[\left(1-\tau_{w}\right) \frac{\alpha_{c}}{1-\alpha_{c}}\right]^{\epsilon_{c}}\left[\frac{A_{m}}{A_{h}}\right]^{\epsilon_{c}-1}
$$

where

$$
\epsilon_{c} \equiv \frac{1}{\left(1-\sigma_{c}\right)} \in[0, \infty)
$$

denotes the elasticity of substitution between market and home consumption. This equation is essentially the same as equation (7) in Rogerson (2008), except that in his case $H_{m}$ refers to hours worked in market services instead of all market consumption. The key insight that we can take away from equation (16) is that the choice of $\epsilon_{c}$ depends critically on how $H_{m} / H_{h}$ and $A_{m} / A_{h}$ behave, which in turn depends critically on what $m$ refers to.

Let us first consider Rogerson's choice of $\epsilon_{c}$ when $m$ refers to market services. We know that structural change implied that hours worked in market services went up. From the evidence we documented above, home hours stayed roughly constant. Hence, $H_{m} / H_{h}$ grew. We know that labor productivity of market services grew whereas the evidence presented above suggests that labor productivity of home production stagnated. Given linear production functions, $A_{m} / A_{h}$ therefore grew. In order to reconcile the behavior of $H_{m} / H_{h}$ with that of $A_{m} / A_{h}$ given equation (16), Rogerson needs to a value $\epsilon_{c}>1$, that is, home and market services need to be substitutes in his utility function. He assumes that $\epsilon_{c}=1.82$.

Now, consider our case in which $m$ refers to market consumption. According to our data listed in Table 2 above, $H_{m} / H_{h}$ fell because market hours fell whereas home hours stayed roughly constant. Moreover, now $A_{m} / A_{h}$ grew more strongly than before, because in the data labor productivity grew more strongly in goods production than in services production. In order to reconcile the patterns of $H_{m} / H_{h}$ and $A_{m} / A_{h}$, we now need $\epsilon_{c}<1$, that is, home and market services need to be complements in the utility function. Our calibration of $\epsilon_{c}=0.76$ does that.

We should add two additional points. First, in a previous version of this paper, we disaggregated market consumption into goods and services and assumed that market services substitute for home services whereas market goods substitute for the aggregate of market and home services. $^{21}$ Consistent with the intuition that we have just developed, we obtained a calibrated

\footnotetext{
${ }^{21}$ We did not pursue this previous version because aggregating market goods and services into market consumption gives the same results and is easier to handle. In particular, it avoids some issues which arose in the previous version because the split into consumed goods and consumed services comes from the final consumption side of NIPA whereas the split into hours worked in goods and service production comes from the value added side of
} 
elasticity between market and home services that was larger than one (the value was reasonably close to that of Rogerson) and a calibrated elasticity between market goods and the service aggregate that was smaller than one. Another way of understanding why our elasticity above comes out as it does is to think of it as a weighted average of these two elasticities. Second, in our analysis, we used MTUS to obtain consistent estimates for market hours, home hours and leisure and used outside information about market hours only for the interpolations. We found that market hours in the U.S. declined somewhat, implying that $H_{m} / H_{h}$ declined. If we had instead used the OECD numbers for market hours worked as Rogerson did, then we would have found that market hours actually increased during this time period; see Figure 2 above. This would have implied that $H_{m} / H_{h}$ increased, instead of decreased. If we had calibrated our model to this case, then we would have ended up with $\epsilon_{c}>1$. Note, however, that the resulting elasticity would still have been smaller than what Rogerson chose. The reason for this is that $H_{m} / H_{h}$ increase less and $A_{m} / A_{h}$ increases more when $m$ refers to market consumption than when $m$ refers to market services.

Second, for similar reasons as those just discussed, our calibrated macro elasticity between market and home produced consumption is smaller than existing micro estimates of that elasticity. In particular, Aguiar and Hurst (2007a) use scanner data and time diaries to document how households substitute time for money through shopping and home production. They estimate that the home production function has an elasticity of around two between time and market goods. The market goods they consider as inputs in home production are a subset of all market consumption that we consider. This implies that they are closer substitutes for home-produced consumption than all market consumption is. Fang and Zhu (2012) obtain an estimate for people who are 25-60, married, and employed. In contrast, our macro elasticity refers to the entire working-age population, and so it includes individuals that are not working in the market at all and therefore tend to have a lower elasticity. Moreover, Fang and Zhu (2012) do not have information about actual home consumption whereas we use our imputed numbers for home value added. Similarly, Rupert et al. (1995) estimate the elasticity of substitution between market and home consumption goods for individuals who are working full time. They use the PSID, which has information only about food consumption. Again, food consumption at home and restaurant meals are much closer substitutes than total home-produced and market-produced consumption.

NIPA. Relating one to the other requires the use of input-output tables, because part of the hours worked in goods and services are used to produce investment goods; see Herrendorf et al. (2013) for the details. 


\section{France}

We now ask how well our model accounts for the French allocation of time between market work, home work, and leisure. We first present our results. We then develop intuition for our results by studying the model version with the linear production function and by conducting counterfactual exercises. We also discuss in some detail the implication of our findings for the marketization of consumption.
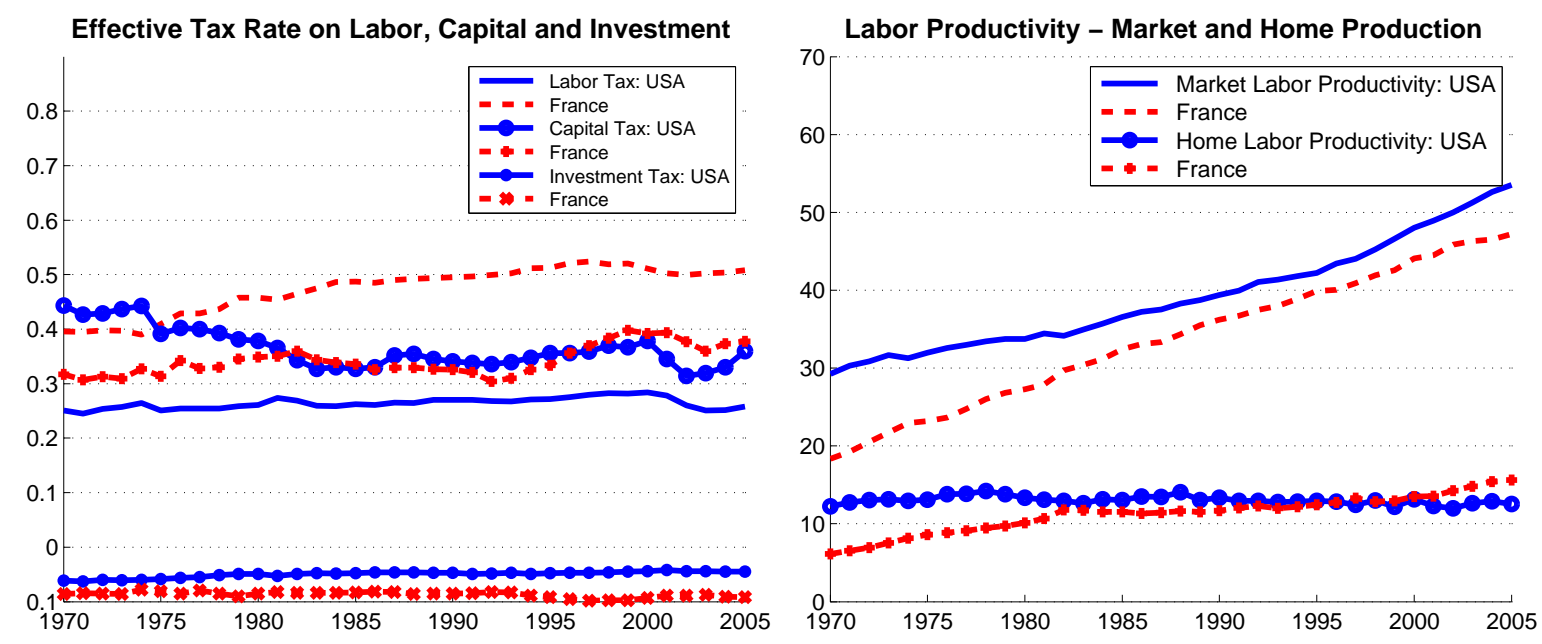

Figure 3: U.S. and French labor productivities and taxes

\subsection{Results}

We leave the calibrated "deep" model parameters unchanged and ask how well our model accounts for the allocation of time in France if we feed into it the French taxes and the French labor-augmenting technical change in market and in home production. Specifically, we take the French taxes again from McDaniel for $t=1970, \ldots, 2005$. We obtain labor-augmenting technical change by targeting the French labor productivities relative to those in the U.S. for $t=1970, \ldots, 2005$ (from OECD for market production and own imputations for home production). We feed into the model the values of $B_{m}(t)^{F R}$ and $B_{h}(t)^{F R}$ for $t=1971, \ldots, 2005$ that match French relative prices of investment in market capital and consumer durables (from the OECD). Lastly, we target the initial and final capital-output ratios in market and home production for $t=1970$ and 2005 (from the OECD and our own calculations).

Figures 3 depict the series for effective taxes and labor productivity in both countries. The left figure shows the well known fact that in France the effective labor income taxes were much larger than in the U.S. Moreover, in France they increased considerably whereas in the U.S. they remained roughly constant on average. Another noteworthy feature of the tax series is that effective capital taxes in the U.S. were initially larger than in France but have came down 


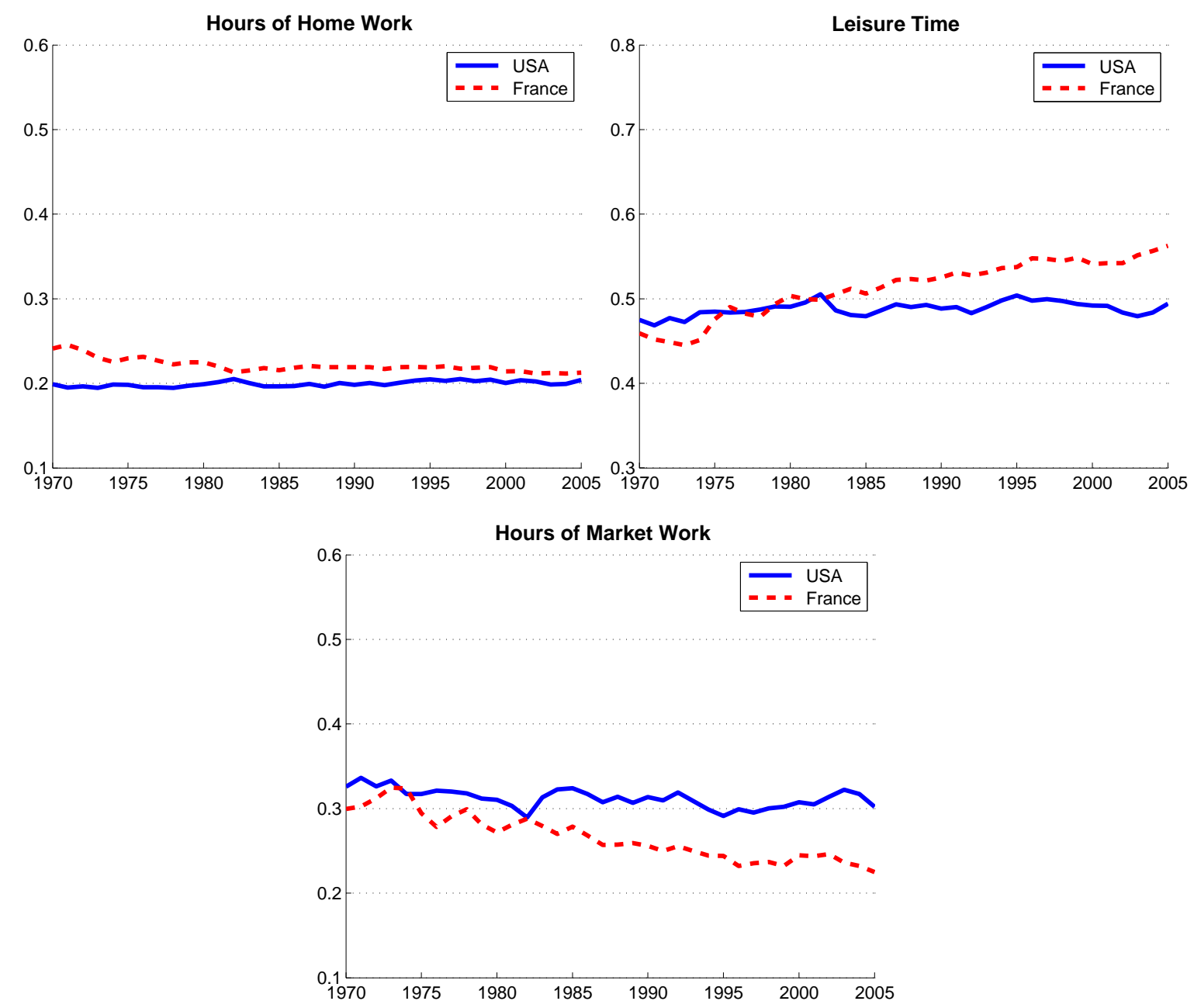

Figure 4: Time Allocation Predicted by the Model 
considerably and are now similar in both countries. The right figure shows that in 1970 there were sizeable gaps between the U.S. and France both in the productivities in the market and at home. Subsequently, France caught up to the U.S. and closed the gaps. In fact, during the last ten years or so, home productivity in France even overtook that in the U.S. This also means that the growth rate of labor productivity in the market and at home are similar in France, which is in stark contrast to the US where labor productivity in the market grew much more strongly than at home.

Table 9: French Hours in the Data and the Model

\begin{tabular}{lccccc}
\hline & & \multicolumn{2}{c}{ Data } & \multicolumn{2}{c}{ Model } \\
& & 1970 & 2005 & 1970 & 2005 \\
\hline Market Hours & $H_{m}$ & 33.5 & 22.7 & 30.0 & 22.5 \\
Home Hours & $H_{h}$ & 23.7 & 22.8 & 24.1 & 21.3 \\
Leisure & $L$ & 42.8 & 54.5 & 45.9 & 56.2 \\
\hline
\end{tabular}

Figure 4 plots the results of feeding in French taxes and productivities. We can see that our model matches the stylized facts that the decline in French market hours was mostly compensated by an increase in French leisure, while home hours changed much less. Table 9 reports the exact numbers for 1970 and 2005. We can see that also quantitatively our model accounts for most of the changes in the French time allocation.

\subsection{Intuition}

To build intuition for the main forces at work in our model, it is useful to simplify our environment such that we can obtain closed-form solutions. To this end, we go back to the linear production functions (15), which imply the closed-form solution for the allocation of market and home hours (16). The intuition for equation (16) goes back to Ngai and Pissarides (2007), who studied how labor gets reallocated in the face of uneven technological progress across sectors $\left(\Delta A_{h} \neq \Delta A_{m}\right.$ in our notation). They showed that if sector outputs are complements in the utility function $\left(\epsilon_{c} \in[0,1)\right.$ in our notation), then uneven technological progress leads to the reallocation of labor to the sector with the slower productivity growth. ${ }^{22}$ Our calibration for the U.S. gave $\epsilon_{c}=0.76$ and $\Delta A_{h}<\Delta A_{m}$. In our context, labor in the U.S. will be therefore be reallocated from market production to home production. Note that the tax term $1-\tau_{w}$ does not show up in Ngai and Pissarides (2007) because they do not consider taxes. As in Rogerson (2008), this term captures that home production is exempt from taxes, implying that an increase

\footnotetext{
${ }^{22}$ In Ngai and Pissarides' application to structural change, this was the service sector. See Herrendorf et al. (2014) for a generalization to non-homothetic CES utility functions.
} 
in labor income taxes leads to the substitution from market to home goods. For our calibration, this effect comes out quantitatively stronger than the previous one, because the exponent $\epsilon_{c}=0.76$ is larger than the exponent $1-\epsilon_{c}=0.24$.

The second step to building intuition is to derive a closed-form solution for leisure. In the simplified environment with linear production functions, leisure depends on the effective labor income taxes, wages, and the price level $P$ associated with the CES aggregator,

$$
P \equiv\left[\alpha_{c}^{\epsilon_{c}}+\left(1-\alpha_{c}\right)^{\epsilon_{c}} p_{h}^{1-\epsilon_{c}}\right]^{\frac{1}{1-\epsilon_{c}}}
$$

where $p_{h}=\left(1-\tau_{w}\right) w / A_{h}$ denotes the shadow price of home production. ${ }^{23}$ In Appendix $\mathrm{C}$ we show that:

$$
L=\frac{1-\alpha_{u}}{\alpha_{u}\left(1-\tau_{w}\right)+\left(1-\alpha_{u}\right)}\left[1-\tau_{w} H_{h}-\frac{\bar{C}}{w / P}\right]
$$

This equation brings out clearly how taxes and real wage growth affect the optimal leisure choice of the stand-in household. First, an increase in $w / P$ implies that $L$ increases, and hence hours worked $1-L$ decrease. Note that if there was no subsistence consumption, i.e., $\bar{C}=0$, then preferences would be homothetic, the income and substitution effects would cancel, and leisure $L$ would not respond to changes in $w / P$. Second, we can see that an increase in $\tau_{w}$ has three effects: it decreases the denominator of (18); it decreases the second term in parenthesis; it decreases $P$ and therefore decreases the third term in parenthesis. The first effect captures the usual substitution from working hours to leisure when income tax increases; the second effect captures that the income tax does not affect home production, implying that the usual effect is smaller in our case; the third effect captures that a tax increase implies an increase in the real wage (because it decreases the price index), which reduces the bite of the subsistence term. One can show that for our parameter values, the net effect is the standard one, that is, an increase in the labor income tax increases leisure.

Equipped with equations (16) and (18), we are now in the position to develop the intuition for our results about the allocation of time among leisure, market production, and home production. We start with the U.S. Since the U.S. is fairly rich already in 1970, real wages are high and $\bar{C} /(w / P)$ is low. Further increases in $w / P$ therefore lead to a quantitatively small decrease in hours worked (in the market and at home) and a quantitatively small offsetting increase in leisure. Given total hours worked, the increase in the labor productivity of market production relative to home production implies that hours are reallocated from market to home production. This effect is relatively small quantitatively because the exponent is small, $1-\epsilon_{c}=0.24$. Since effective labor income taxes do not change much, they do not change the allocation of time.

\footnotetext{
${ }^{23}$ With a linear production function, $p_{h}=\left(1-\tau_{w}\right) w / A_{h}$ is the shadow price of home production because one unit of home production requires $1 / A_{h}$ units of time, which has a market price of $\left(1-\tau_{w}\right) w$.
} 
The net effects are as follows: leisure increases somewhat, market hours decrease somewhat, and home hours do not change much. The latter happens because the opposing effects from changes in $\bar{C} /(w / P)$ and $A_{m} / A_{h}$ turn out to offset each other quantitatively.

We continue with France. In 1970, real wages were still considerably lower than in the U.S. The subsequent increases in $w / P$ therefore lead to a quantitatively sizeable decrease in hours worked and an offsetting increase in leisure. The fact that the increases in the labor productivities of market and home production are similar implies there is hardly any reallocation between market and home hours through this margin. The increase in labor income taxes implies that hours are reallocated from market to non-market uses, so both home work and leisure increase as a result. This effect is sizeable quantitatively, as the elasticity of substitution between market and home consumption is close to one. The net effects are that leisure increases strongly, market hours decrease strongly, and home hours decrease somewhat but in comparison to the other two changes, this change is small. The latter happens because it turns out that, again, the opposing effects from $\bar{C} /(w / P)$ and $\tau_{w}$ offset each other quantitatively.

\subsection{Marketization of consumption}

Freeman and Schettkat (2005) argued that one important reason for the employment gap between the U.S. and Germany is differences in the marketization of services, that is, Americans buy many services in the market that Germans produce at home. In this subsection, we ask whether our evidence is consistent with the marketization hypothesis for the U.S. and France. There might be some initial doubt because we found that home hours behave in similar ways in the U.S. and France. However, this does not contradict the marketization hypothesis because at the same time market hours in France declined much more strongly than in the U.S. As a result, the ratio of market-to-home hours declined a lot in France and little in the U.S. In other words, the evidence on hours suggests that in France the marketization of services did not happen to the same extent as in the U.S. However, to draw that conclusion we need additional information on how the composition of consumption behaved in the two countries.

Looking at market and home produced consumption, instead of at market and home hours worked, the marketization hypothesis comes through very clearly. Figure 5 depicts the ratios of market-to-home-produced consumption in the data and the model, normalizing the U.S. market-to-home consumption ratio to one in 1970 and expressing the French ratio relative to U.S. (that is, using the 1970 U.S. relative price of the two consumptions also for France). We can see that this ratio increased strongly in the U.S. while it declined in France. In other words, the U.S. experienced a marketization of consumption and France experienced the opposite. We emphasize that to reach this conclusion, we need the imputed value added of home production in both the U.S. and France.

Our model is qualitatively consistent with the marketization patterns in the U.S. and France. 
To understand the reason for this, it is useful to go back to the static special case that we used in the previous subsection to develop intuition. As expression (15) shows, both market and home produced consumption are then the products of labor productivity $A_{j}$ and hours worked $H_{j}$. In this case, it is straightforward to deduce what happens to the consumption ratio: in the U.S. labor productivity has strongly increased in the market but remained flat at home at the same time as which market hours and home hours have not changed much. Hence, market consumption must have gone up relative to home consumption. In contrast, in France the increases in the labor productivities of market and home production were similar at the same time as which French market hours declined and home hours did not change much. Hence, market consumption must have declined relative to home consumption. This is exactly what Figure 5 depicts.

Figure 5: Marketization of consumption in the data and the model
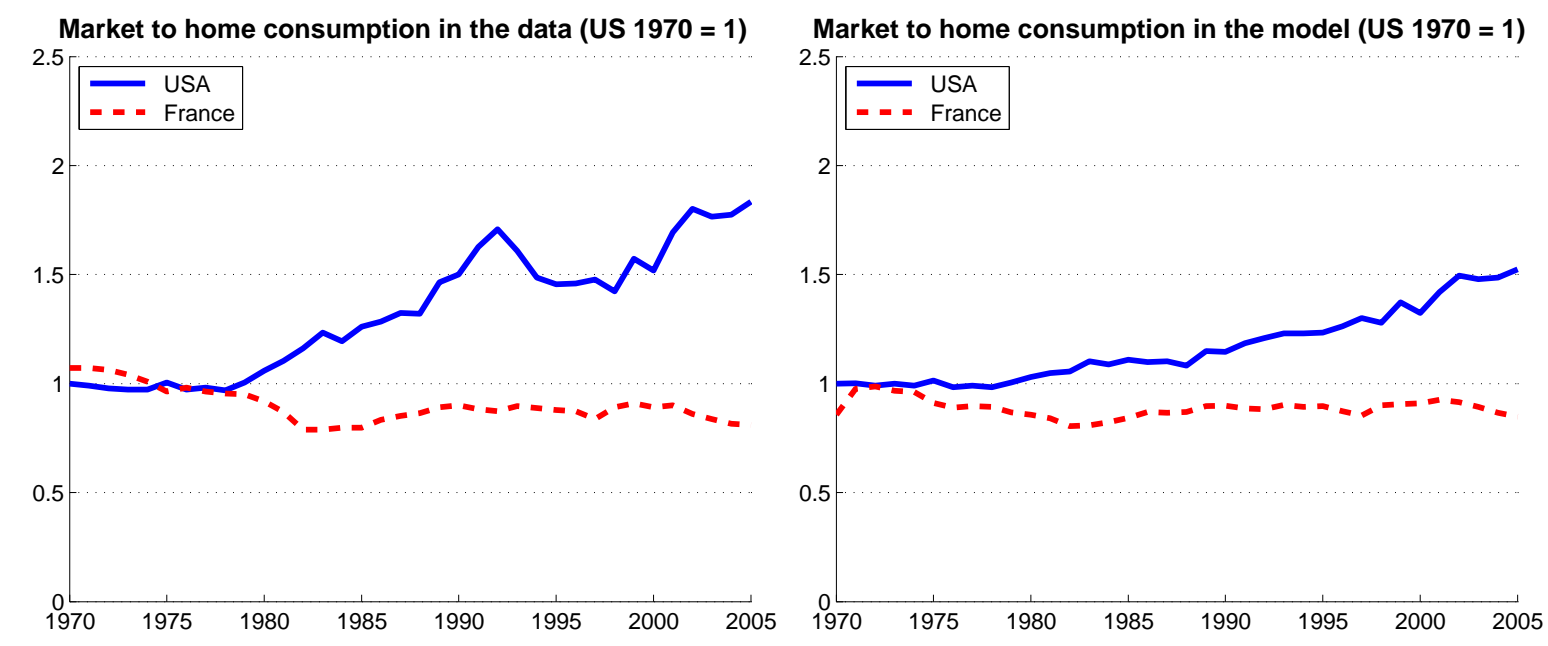

\subsection{Counterfactual exercises}

A different way of building intuition for the key forces at work in our model is to conduct counterfactual exercises. In what follows we will report two such exercises, which will serve to establish that differences between U.S. and French effective labor income taxes are largely responsible for the differences in the time allocation and that it is critical to use imputed home labor productivities, instead of calibrated ones.

The first counterfactual exercise assesses how the U.S. time allocation would change if the U.S. adopted French effective labor-income taxes. To this end, we feed French effective laborincome taxes into the otherwise unchanged U.S. economy. Figure 6 shows the results. We can see that the differences in labor income taxes are responsible for a large part of the differences in the time allocation, in particular between market and non-market time. This is consistent with the findings of Prescott (2004) that differences in labor income taxes account for a large 

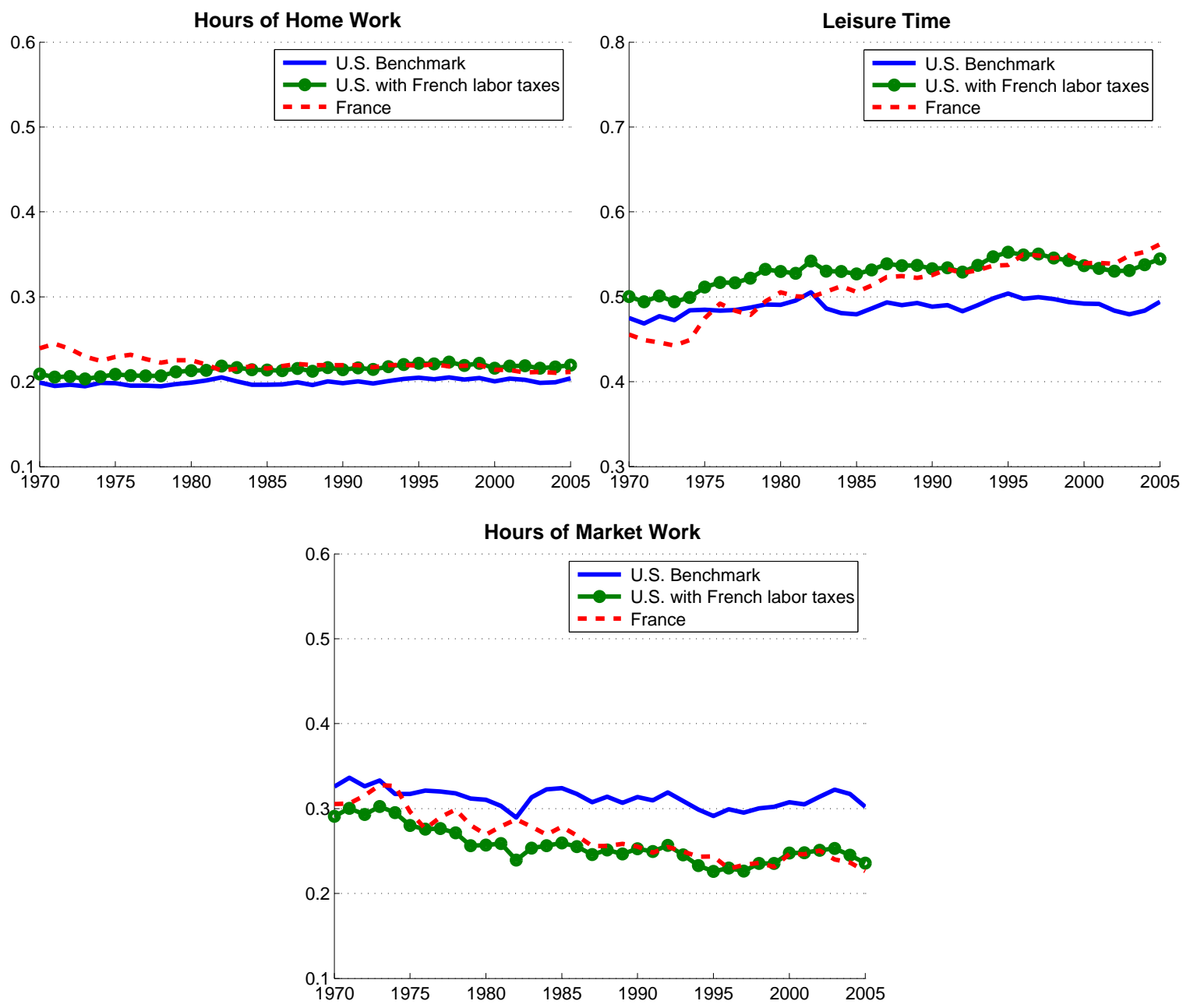

Figure 6: U.S. with French labor-income taxes 
part of the differences in market hours between the U.S. and Continental Europe. We can also see that at the beginning of the sample, effective labor income taxes alone do not account for the differences in the behavior of hours worked at home and leisure. This suggests that the other differences between France and the U.S. have a role to play too.

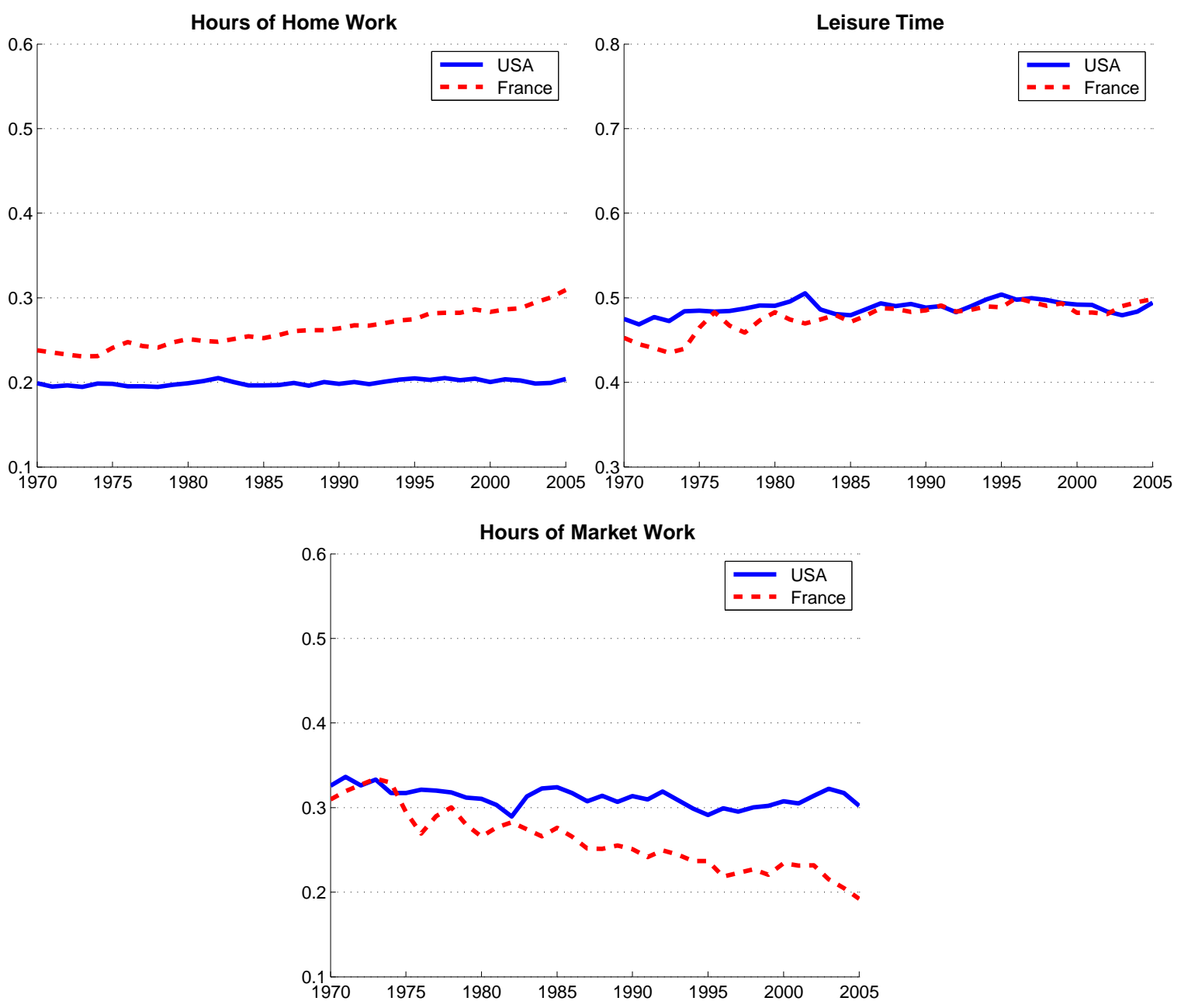

Figure 7: France with U.S. home technology

The second counterfactual exercise assesses how the French time allocation would change if instead of technological progress that we imputed, the French experience the technological regress of the U.S. To this end, we follow the literature and assume that technological change at home relative to the market behaves in the same way in France as in the U.S.:

$$
\frac{A_{h}^{F R}(t)}{A_{m}^{F R}(t)}=\frac{A_{h}^{U S}(t)}{A_{m}^{U S}(t)}
$$

We leave all other parameter values of the French economy unchanged. Figure 7 shows that we then get the counterfactual implication that French home hours rise. This establishes that it is 
crucial for obtaining our results that we target the measured French labor productivity of home production, instead of calibrating it. The intuitive reason for why French home hours rise when we give France the relative U.S. technological progress at home is closely linked to the fact that our calibration home and market consumption are complements. A reduction in French home labor productivity then leads to an increase in French home hours relative to market hours (see Equation (16) for the precise expression in the static special case of our model).

We draw two conclusions from the counterfactual exercises. First, effective labor income taxes are a key driver of the different time allocations in the U.S. and France. Second, to generate the time allocation in France, it is crucial to use measured home labor productivity.

\section{Conclusion}

We have documented new facts about the time allocations in the U.S. and France since 1970. During the last forty years, market hours per working-age population decreased and leisure increased while hours devoted to home production change less in comparison. We have asked what accounts for the time allocations in the U.S. and France. To answer this question, we have build a version of the growth model with market production, and home production and with capital in the production of home and market output. We have found that differences in effective income taxes and in labor productivities are the key forces behind the differences in the time allocations in the U.S. and France. In this context, it has been crucial to use measured, instead of calibrated, labor productivity of home production.

The natural next steps for future research are to extend the analysis to other countries, and to understand why technological change at home behaves so differently in the U.S. and France. We plan to pursue more seriously than in our discussion above how important it was in this context that many women entered the labor force in the U.S. Beyond that, we believe that the production of leisure warrants more attention. While this is typically not modeled at all, many of the same considerations as for home work apply also to the production of leisure. We think that this is an important and promising subject for future research.

\section{References}

Aguiar, Mark and Eric Hurst, "Life-cycle Prices and Production," American Economic Review, 2007, 97, 1533-1559.

— and — , "Measuring Leisure: The Allocation of Time Over Five Decades," Quarterly Journal of Economics, 2007, 122, 969-1006. 
— Erik Hurst, and Loukas Karabarbounis, "Time Use during the Great Recession," American Economic Review, 2013, 103, 1664-1696.

Becker, Garry S., "A Theory of the Allocation of Time," Economic Journal, 1965, 75, 493517.

Benhabib, Jess, Richard Rogerson, and Randall Wright, "Homework in Macroeconomics: Household Production and Aggregate Fluctuations," Journal of Political Economy, 1991, 99, $1166-1187$.

Bick, Alexander, "The Quantitative Role of Child Care for Female Labor Force Participation and Fertility," Manuscript, Arizona State University 2014.

and Nicola Fuchs-Schuendeln, "Taxation and Labor Supply of Married Couples across Countries: A Macroeconomic Analysis,” Manuscript, Arizona State University 2014.

_ Bettina Brueggemann, and Nicola Fuchs-Schuendeln, "Labor Supply Along the Extensive and Intensive Margin: Cross-Country Facts and Time Trends by Gender," Manuscript, Arizona State University 2014.

Bridgman, Benjamin R., "Home Productivity," Manuscript, Buerau of Economic Analysis 2013.

— Georg Duernecker, and Berthold Herrendorf, "Household Production in OECD Countries,” Manuscript, Arizona State University 2014.

Burda, Michael C., Daniel S. Hamermesh, and Philippe Weil, "The Distribution of Total Work in the EU and US," in Tito Boeri, Michale C. Burda, and Francis Kramarz, eds., Working Hours and Job Sharing in the EU and the USA: Are Europeans Lazy? Are Americans Crazy?, Oxford: Oxford University Press, 2008.

Fang, Lei and Cara McDaniel, "Trends in Home Hours in the U.S and Europe," Manuscript, Arizona State University and Federal Reserve Bank of Atlanta 2014.

— and Guozhong Zhu, "Home Production Technology and Time Allocation: Empirics, Theory, and Implications," Working Paper 2012-19, Federal Reserve Bank of Atlanta 2012.

Fisher, Jonas, "Why Does Household Investment Lead Business Investment Over the Business Cycle?," Journal of Political Economy, 2007, 115, 141-168.

Freeman, Richard B. and Ronald Schettkat, "Marketization of Production and the USEurope Employment Gap," Oxford Bulletin of Economics and Statistics, 2001, 63, 647-670. 
— and - "Marketization of Household Production and the EU-US Gap in Work," Economic Policy, 2005, 20, 7-50.

Gimenez-Nadal, Jose Ignacio and Almudena Sevilla-Sanz, "Trends in Time Allocation: A Cross-Country Analysis," European Economic Review, 2012, 56, 1338-1359.

Greenwood, Jeremy, Ananth Seshadri, and Mehmet Yorukogly, "Engines of Liberation," Review of Economic Studies, 2005, 72, 100-133.

and Zvi Hercowitz, “The Allocation of Capital and Time over the Business Cycle," Journal of Political Economy, 1991, 99, 1188-1214.

Guner, Nezih, Remzi Kaygusuz, and Gustavo Ventura, "Taxation and Household Labor Supply," Review of Economic Studies, 2012, 79, 1113-1149.

$\longrightarrow$, — Economics, 2012, 59, 111-128.

Herrendorf, Berthold, Richard Rogerson, and Ákos Valentinyi, “Two Perspectives on Preferences and Structural Transformation," American Economic Review, 2013, 103, 2752-2789.

$\longrightarrow$, - and —, "Growth and Structural Transformation," in Philippe Aghion and Steven N. Durlauf, eds., Handbook of Economic Growth, Vol. 2, Elsevier, 2014, pp. 855941.

House, Christopher, John Laitner, and Dmitriy Stolyarov, "Valuing Lost Home Production of Dual Earner Couples,” International Economic Review, 2008, 49, 701-736.

Juster, F. Thomas and Frank P. Stafford, "The Allocation of Time: Empirical Findings, Behavioral Models, and Problems of Measurement," Journal of Economic Literature, 1991, $29,471-522$.

Kendrick, John W., "Expanding Imputed Values in the National Income and Product Accounts," Review of Income and Wealth, 1979, 25, 349-363.

Landefeld, J. Steven, Barbara M. Fraumeni, and Cindy M. Vojtech, "Accounting for Household Production: A Prototype Satellite Account Using the American Time Use Survey," Review of Income and Wealth, 2009, 55, 205-225.

McDaniel, Cara, "Average Tax Rates on Consumption, Investment, Labor and Capital in the OECD 1950-2003," Manuscript, Arizona State University 2007.

— , "Forces Shaping Hours Worked in the OECD, 1960-2004," American Economic Journal: Macroeconomics, 2011, 3, 27-52. 
Ngai, L. Rachel and Barbara Petrongolo, "Gender Gaps and the Rise of the Service Economy," Manuscript, London School of Economics 2013.

and Chrisopher A. Pissarides, "Structural Change in a Multisector Model of Growth," American Economic Review, 2007, 97, 429-443.

and —-, "Trends in Hours and Economic Growth," American Economic Journal: Macroeconomics, 2008, 11, 239-256.

— and —- "Taxes, Social Subsidy, and the Allocation of Work Time," Review of Economic Dynamics, 2011, 3, 1-26.

Ohanian, Lee E., Andrea Raffo, and Richard Rogerson, "Long-term Changes in Labor Supply and Taxes: Evidence from OECD Countreis, 1956-2004," Journal of Monetary Economics, 2008, 55, 1353-1362.

Olovsson, Conny, "Why do Europeans Work so Little?," International Economic Review, 2009, 50, 39-61.

Prescott, Edward C., "Why Do Americans Work So Much More Than Europeans?," Federal Reserve Bank of Minneapolis Quarterly Review, 2004, 2-13, 28.

Ragan, Kelly S., "Taxes and Time Use: Fiscal Policy in a Household Production Model," American Economic Journal: Macroeconomics, 2013, 5, 168-192.

Ramey, Valerie A., "Time Spent in Home Production in the Twentieth-Century United States: New Estimates from Old Data," Journal of Economic History, 2009, 69, 1-47.

Ramey, Valery A. and Neville Francis, "A Century of Work and Leisure," American Economic Journal: Macroeconomics, 2009, 1, 189-224.

Rendall, Michelle, "The Rise of the Service Sector and Female Market Work: Europe vs. US," Technical Report, University of Zurich 2010. Manuscript.

Restuccia, Diego and Guillaume Vandenbroucke, "A Century of Human Capital and Hours," Economic Inquiry, 2013, 51, 1849-1866.

— and - "forthcoming: Explaining Educational Attainment across Countries and over Time," Review of Economic Dynamics, 2014.

Rogerson, Richard, “Taxation and Market Work: is Scandinavia an Outlier?," Economic Theory, 2007, 32, 59-85. 
— , "Structural Transformation and the Deterioration of European Labor Market Outcomes," Journal of Political Economy, 2008, 116, 235-259.

Rupert, Peter, Richard Rogerson, and Randall Wright, "Estimating Substitution Elasticities in Household Production Models," Economic Theory, 1995, 6, 179-193.

Schreyer, Paul and W. Erwin Diewert, "Household Production, Leisure, and Living Standards," in Dale W. Jorgenson, J. Steven Landefeld, and Paul Schreyer, eds., Measuring Economic Sustainability and Progress, Chicago, IL: University of Chicago Press, 2014. 


\section{Appendix A: Details of the Data Work}

\section{Appendix A.1: Background Information to Times Use Surveys}

Table 10: Dates of times use surveys and number of participants

\begin{tabular}{lrrrrrrrr}
\hline U.S. & 1965 & 1975 & 1985 & 1992 & 1994 & 1998 & 2003 & 2004 \\
\hline Total & 1,965 & 5,807 & 2,539 & 6,178 & 937 & 1,720 & 16,760 & 11,187 \\
Males & 1,082 & 3,264 & 1,340 & 3,307 & 543 & 977 & 9,320 & 6,204 \\
Females & 883 & 2,543 & 1,199 & 2,871 & 394 & 743 & 7,440 & 4,983 \\
& & & & & & & & \\
& & & 2005 & 2006 & 2007 & 2008 & 2009 & 2010 \\
\hline Total & & & 10,564 & 10,440 & 9,808 & 10,199 & 10,344 & 10348 \\
Males & & & 5,902 & 5,872 & 5,434 & 5,558 & 5,780 & 5,686 \\
Females & & & 4,662 & 4,568 & 4,374 & 4,641 & 4,564 & 4,662
\end{tabular}

\begin{tabular}{lrrrrr}
\hline France & 1965 & 1974 & 1985 & 1998 & 2010 \\
\hline Total & 2,898 & 4,633 & 16,047 & 12,393 & 27,903 \\
Males & 1,460 & 2,202 & 7,455 & 5,987 & \\
Females & 1,438 & 2,431 & 8,592 & 6,406 &
\end{tabular}

\begin{tabular}{lrrr}
\hline Germany & 1965 & 1991 & 2001 \\
\hline Total & 2,137 & 21,801 & 27,583 \\
Males & 945 & 10,531 & 12,827 \\
Females & 1,192 & 11,270 & 14,756
\end{tabular}

\begin{tabular}{lrrrrrrr}
\hline UK & 1961 & 1974 & 1983 & 1987 & 1995 & 2000 & 2005 \\
\hline Total & 8,360 & 14,301 & 7,432 & 10,841 & 1,422 & 14,169 & 3,614 \\
Males & 4,163 & 6,753 & 2,934 & 5,001 & 679 & 6,520 & 1,646 \\
Females & 4,197 & 7,548 & 4,498 & 5,840 & 743 & 7,649 & 1,968 \\
\hline
\end{tabular}


Table 11: Definitions of market work, home work, and leisure

\begin{tabular}{lll}
\hline $\begin{array}{l}\text { Home work: AV 6:11 } \\
\text { Personal care: AV 13,14,16 }\end{array}$ & $\begin{array}{l}\text { Leisure: AV 12,15,17:40 } \\
\text { Education: AV 4 }\end{array}$ & $\begin{array}{l}\text { Market work: AV 1:3,5 } \\
\text { (AV stands for Activity) }\end{array}$ \\
\hline & AV 15 Meals and snacks & AV 29 Visit friends at their homes \\
AV 1 Paid work & AV 16 Sleep & AV 30 Listen to radio \\
AV 2 Paid work at home & AV 17 Free time travel & AV 31 Watch television or video \\
AV 3 Paid work, second job & AV 18 Excursions & AV 32 Listen to records, tapes, cds \\
AV 4 School, classes & AV 19 Active sports participation & AV 33 Study, home work \\
AV 5 Travel to/from work & AV 20 Passive sports participation & AV 34 Read books \\
AV 6 Cook, wash up & AV 21 Walking & AV 35 Read papers, magazines \\
AV 7 Housework & AV 22 Religious activities & AV 36 Relax \\
AV 8 Odd jobs & AV 23 Civic activities & AV 37 Conversation \\
AV 9 Gardening & AV 24 Cinema or theatre & AV 38 Entertain friends at home \\
AV 10 Shopping & AV 25 Dances or parties & AV 39 Knit, sew \\
AV 11 Childcare & AV 26 Social clubs & AV 40 Other leisure \\
AV 12 Domestic travel & AV 27 Pubs & \\
AV 13 Dress/personal care & AV 28 Restaurants & \\
AV 14 Consume personal services &
\end{tabular}

\section{Appendix A.2: Interpolation and Extrapolation of Hours}

\section{Interpolation of hours}

- Suppose we have time use data for 1965 and 1975 (as in the case of the U.S., for instance).

- Market hours. The average weekly time spent on market work (for individuals between 15 and 64 years) in 1965 and 1975 are equal to $H_{m}(65)=34.9$ hours and $H_{m}(75)=30.6$ hours respectively. We want to obtain a smooth interpolation which is based on the actual evolution of hours of work. To this end, we look at the evolution of average annual market hours per working age person between these two points in time. The data for market hours per working age person are taken from the GGDC database.

- Step 1: Annual hours of market work per working age person are in row (1) of the table below.

- Step 2: Compute the "forward" change in hours for each year with respect to the start year 1965. That is: $H(65) / H(65), H_{66} / H(65), H_{67} / H(65), \ldots, H(75) / H(65)$. See row (2).

- Step 3: Compute the "backward" change in hours for each year with respect to the final year 1975. That is: $H(75) / H(75), H(74) / H(75), H(73) / H(75), \ldots, H(65) / H(75)$. See row (3). 
Table 12: Aggregation in different time-use studies

\begin{tabular}{|c|c|c|c|c|}
\hline & Market work & Home work & Leisure & Other \\
\hline $\mathbf{R}$ & & $\begin{array}{l}\text { food preparation, cooking, set ta- } \\
\text { ble, wash/put away dishes, clean- } \\
\text { ing, laundry, ironing, clothing re- } \\
\text { pair, home repairs, maintain vehicle, } \\
\text { other domestic work, purchase routine } \\
\text { goods, purchase consumer durables, } \\
\text { purchase repair, laundry services, fi- } \\
\text { nancial/government services, purchase } \\
\text { other services, care of infants, general } \\
\text { care of older children, medical care of } \\
\text { children, supervise child or help with } \\
\text { homework, read to, talk with child, } \\
\text { other child care, adult care, travel re- } \\
\text { lated to consumption, travel related to } \\
\text { child care }\end{array}$ & & $\begin{array}{l}\text { Excluded: } \\
\text { purchase per- } \\
\text { sonal services, } \\
\text { purchase med- } \\
\text { ical services, } \\
\text { personal or } \\
\text { adult care } \\
\text { travel }\end{array}$ \\
\hline $\mathbf{A}-\mathbf{H}$ & $\begin{array}{l}\text { Total market work: } \\
\text { work at main or other } \\
\text { jobs, paid work at } \\
\text { home, travel to/from } \\
\text { work, meals/breaks at } \\
\text { work, job search }\end{array}$ & $\begin{array}{l}\text { Total non-market work meal prepa- } \\
\text { ration and cleanup, laundry, ironing, } \\
\text { dusting, vacuuming, indoor household } \\
\text { cleaning, indoor design and main- } \\
\text { tenance, acquiring goods or service } \\
\text { (excluding medical care, education, } \\
\text { restaurant meals), home maintenance, } \\
\text { outdoor cleaning, vehicle repair, gar- } \\
\text { dening, and pet care }\end{array}$ & $\begin{array}{l}\text { Leisure 1: watching TV, reading, par- } \\
\text { ties, relaxing, bars, sports, visiting } \\
\text { friends, gardening, pets } \\
\text { Leisure 2: Leisure } 1+\text { sleep time, eat- } \\
\text { ing, personal care } \\
\text { Leisure 3: Leisure } 2+\text { child care } \\
\text { Leisure 4: Leisure } 3 \text { + education, } \\
\text { civic and religious activities, adult } \\
\text { care, own medical care. }\end{array}$ & $\begin{array}{l}\text { Total child } \\
\text { care: primary, } \\
\text { educational, } \\
\text { recreational } \\
\text { child care }\end{array}$ \\
\hline
\end{tabular}

R: Ramey (JEHist, 2009), A-H: Aguiar and Hurst (QJE, 2007), D-H: Duernecker and Herrendorf (2014) 
- Step 4: Compute the implied weekly, "forward" hours for each year as: $H_{m}(66)^{f}=$ $H_{m}(65) * H_{66} / H(65), H_{m}(67)^{f}=H_{m}(65) * H_{67} / H(65), \ldots, H_{m}(75)^{f}=H_{m}(65) *$ $H(75) / H(65)$. See row (4)

- Step 5: Compute the implied weekly, "backward" hours for each year as: $H_{m}(74)^{b}=$ $H_{m}(75) * H(74) / H(75), H_{m, 73}^{b}=H_{m}(75) * H(73) / H(75), \ldots, H_{m}(65)^{b}=H_{m}(75) *$ $H(65) / H(75)$. See row $(5)$

- Step 6: Interpolation. Taking the simple average of these two series is not an option because the resulting series would not go through the actual period-start and -end points. Instead, we do a weighted interpolation: $H_{m}(66)=\left(9 * H_{m}(66)^{f}+1 *\right.$ $\left.H_{m}(66)^{b}\right) / 10, H_{m}(67)=\left(8 * H_{m}(67)^{f}+2 * H_{m}(67)^{b}\right) / 10, \ldots, H_{m}(74)=\left(1 * H_{m}(74)^{f}+\right.$ $\left.9 * H_{m}(74)^{b}\right) / 10$. See row (6), which is our final series for hours of market work.

Table 13: Interpolation of market hours

\begin{tabular}{rrrrrrrrrrrrr}
\hline & 1965 & 1966 & 1967 & 1968 & 1969 & 1970 & 1971 & 1972 & 1973 & 1974 & 1975 \\
\hline (1) & 1194.6 & 1207.2 & 1199.6 & 1196.8 & 1201.5 & 1167.7 & 1144.1 & 1159.6 & 1172.0 & 1160.1 & 1114.4 \\
(2) & 1.000 & 1.010 & 1.004 & 1.002 & 1.006 & 0.978 & 0.958 & 0.971 & 0.981 & 0.971 & 0.933 \\
$(3)$ & 1.072 & 1.083 & 1.076 & 1.074 & 1.078 & 1.048 & 1.027 & 1.041 & 1.052 & 1.041 & 1.000 \\
(4) & 34.9 & 35.3 & 35.1 & 35.0 & 35.1 & 34.1 & 33.4 & 33.9 & 34.3 & 33.9 & 32.6 \\
$(5)$ & 32.8 & 33.2 & 33.0 & 32.9 & 33.0 & 32.1 & 31.4 & 31.9 & 32.2 & 31.9 & 30.6 \\
(6) & $\mathbf{3 4 . 9}$ & 35.1 & 34.6 & 34.3 & 34.3 & 33.1 & 32.2 & 32.5 & 32.6 & 32.1 & $\mathbf{3 0 . 6}$ \\
\hline
\end{tabular}

There are two different ways of computing home hours (and leisure). Let's start with Approach (i)

- Total hours - Approach (i). To be able to compute leisure and home hours, we, first, need a series for total disposable time. From the time use we have the total weekly disposable time in 1965 and 1975: $H(65)+L(65)=100.9$ hours and $H(75)+L(75)=102.4$ hours.

- Step 1: Compute the percentage of market hours in total hours in 1965 and 1975. See rows (1) [total weekly time in hours], (2) [weekly market hours], (3) share of weekly market hours in total time.

- Step 2: Linearly interpolate between the start- and the end-percentage. See row (4).

- Step 3: Recover the total time for each year by dividing the market hours by the share of market hours. See row (5). 
- Home hours - Approach (i). The time use data gives us two observations for home hours: $H_{h, 65}=20.6$ and $H_{h, 75}=20.0$.

- Step 1: Compute the share of weekly home hours in total weekly hours for 1965 and 1975. See rows (6) [total weekly time in hours], (7) [weekly home hours], (8) share of weekly home hours in total time.

- Step 2: Linearly interpolate between the start- and the end-percentage. See row (9).

- Step 3: Compute weekly home hours by multiplying the total weekly time by the share of home hours. See row (10).

- Leisure - Approach (i). The series for leisure is obtained by subtracting market hours and home hours from the total weekly time. See row (11).

Table 14: Interpolation of total time, home hours and leisure, Approach (i)

\begin{tabular}{rrrrrrrrrrrr}
\hline & 1965 & 1966 & 1967 & 1968 & 1969 & 1970 & 1971 & 1972 & 1973 & 1974 & 1975 \\
\hline & & & & & & & & & & & \\
$(1)$ & 100.9 & & & & & & & & & & 102.4 \\
$(2)$ & 34.9 & & & & & & & & & & 30.6 \\
$(3)$ & 34.6 & & & & & & & & & & 29.9 \\
$(4)$ & 34.6 & 34.1 & 33.7 & 33.2 & 32.7 & 32.3 & 31.8 & 31.3 & 30.8 & 30.4 & 29.9 \\
$(5)$ & 100.9 & 102.7 & 102.9 & 103.5 & 104.7 & 102.6 & 101.4 & 103.7 & 105.7 & 105.6 & 102.4 \\
\hline$(6)$ & 100.9 & & & & & & & & & & 102.4 \\
$(7)$ & 20.6 & & & & & & & & & & 20.0 \\
$(8)$ & 20.4 & & & & & & & & & & 19.5 \\
$(9)$ & 20.4 & 20.3 & 20.2 & 20.2 & 20.1 & 20.0 & 19.9 & 19.8 & 19.7 & 19.6 & 19.5 \\
$(10)$ & 20.6 & 20.9 & 20.8 & 20.9 & 21.0 & 20.5 & 20.2 & 20.5 & 20.8 & 20.7 & 20.0 \\
$(11)$ & 45.4 & 46.8 & 47.4 & 48.3 & 49.5 & 49.0 & 49.0 & 50.7 & 52.3 & 52.9 & 51.8 \\
\hline
\end{tabular}

We now turn to Approach (ii).

- Total hours - Approach (ii). From the time use we have the total time in 1965 and 1975: $H(65)+L(65)=100.9$ and $H(75)+L(75)=102.4$.

- Step 1: Linearly interpolate between the start and the end values of total time. See row (1).

- Step 2: Compute the share of home hours in non-market time for 1965 and 1975 and linearly interpolate between the start and the end points. See row (2). 
- Home hours - Approach (ii): Compute home hours for each year by multiplying the non-market time with the share of home hours in non-market time. Row (3).

- Leisure - Approach (ii). The series for leisure is obtained by subtracting market hours and home hours from the total weekly time. See row (4).

Table 15: Interpolation of total time, home hours and leisure, Approach (ii)

\begin{tabular}{rrrrrrrrrrrrr}
\hline year & 1965 & 1966 & 1967 & 1968 & 1969 & 1970 & 1971 & 1972 & 1973 & 1974 & 1975 \\
$(1)$ & 100.9 & 101.0 & 101.2 & 101.3 & 101.5 & 101.6 & 101.8 & 101.9 & 102.1 & 102.2 & 102.4 \\
$(2)$ & 31.2 & 30.9 & 30.6 & 30.2 & 29.9 & 29.5 & 29.2 & 28.8 & 28.5 & 28.2 & 27.8 \\
$(3)$ & 20.6 & 20.4 & 20.3 & 20.2 & 20.1 & 20.2 & 20.3 & 20.0 & 19.8 & 19.8 & 20.0 \\
$(4)$ & 45.4 & 45.6 & 46.2 & 46.8 & 47.1 & 48.3 & 49.3 & 49.4 & 49.7 & 50.4 & 51.8 \\
\hline
\end{tabular}

- Résumé: We favor Approach (ii) for the following reason: Approach (i) implies a strong co-movement between market hours and total time. For instance, between 1974 and 1975, we see a decline in market hours from 32.1 to 30.6 weekly hours. At the same time, total hours drop from 105.6 to 102.4. Moreover, the series for total time is very volatile (because it's directly linked to market hours which fluctuate a lot). This is somewhat counterfactual - at least for the U.S. In the late 2000s, we have annual time use observations and we see that individuals change their total weekly time $\left(H_{m}+H_{h}+L\right)$ typically by less than an hours from one year to the next. Approach (ii) is consistent with this observations because it linearly interpolates the total time and does not link it to market hours.

\section{Extrapolation of hours}

For some countries we need to extrapolate the hours series. For instance, the last time use observation for France is for 1998 but we want to know what the hours are in 2005 . There are three different ways to do the extrapolation. All three approaches use the same way to compute market hours. So let's first look at how market hours are computed.

- Suppose we are looking at France, we have time use data for 1998, and we want to extrapolate the series until 2005.

- Market hours. The weekly market hours in 1998 are equal to $H m(98)=24.5$. As above, we make use of the data on the evolution of actual hours of work per working age person.

- Step 1: Market hours per working age person are in row (1) of the table below . 
- Step 2: Compute the change in hours for each year with respect to the start year 1998. That is: $H(98) / H(98), H_{(99)} / H(98), H(00) / H(98), \ldots, H(05) / H(98)$. See row (2).

- Step 3: Compute the implied weekly hours for each year as: $H_{m}(99)^{f}=H m(98) *$ $H(99) / H(098), H_{m}(00)^{f}=H m(98) * H(00) / H(098), \ldots, H_{m}(05)^{f}=H m(98) *$ $H(05) / H(098)$. See row (3)

Table 16: Extrapolation of market hours

\begin{tabular}{rrrrrrrrr}
\hline year & 1998 & 1999 & 2000 & 2001 & 2002 & 2003 & 2004 & 2005 \\
\hline & & & & & & & & \\
(1) & 1005.4 & 1018.2 & 1014.1 & 1016.6 & 989.3 & 981.3 & 994.0 & 989.3 \\
(2) & 1.000 & 1.013 & 1.009 & 1.011 & 0.984 & 0.976 & 0.989 & 0.984 \\
$(3)$ & $\mathbf{2 4 . 5}$ & 24.8 & 24.7 & 24.8 & 24.1 & 23.9 & 24.2 & 24.1 \\
\hline
\end{tabular}

Now let's look at the three approaches to compute home hours and leisure in greater detail.

- Total hours - Approach (1). We, first, need a series for total disposable time. From the time use we have the total time in 1998 which is: $H(098)+L(098)=106.0$.

- Step 1: Compute the share of market hours in total hours in 1998. See rows (1) [total weekly time in hours], (2) [weekly market hours], (3) share of weekly market hours in total time.

- Step 2: Assume that this share remains constant during the period from 1998 to 2005. See row (4).

- Step 3: Recover the total time for each year by dividing the market hours by the share of market hours. See row (5).

- Home hours - Approach (1). The time use data gives us an observations for home hours in 1998: $H_{h, 98}=24.1$.

- Step 1: Compute the share of weekly home hours in total weekly hours for 1998. See rows (6) [total weekly time in hours], (7) [weekly home hours], (8) share of weekly home hours in total time.

- Step 2: Assume that this share is constant during the period from 1998 to 2005. See row (9). 
- Step 3: Compute weekly home hours by multiplying the total weekly time by the share of home hours. See row (10).

- Step 4: The series for leisure is obtained by subtracting market hours and home hours from the total weekly time. See row (11).

Table 17: Extrapolation of total time, home hours and leisure, Approach 1

\begin{tabular}{rrrrrrrrr}
\hline year & 1998 & 1999 & 2000 & 2001 & 2002 & 2003 & 2004 & 2005 \\
\hline & & & & & & & & \\
(1) & 106.0 & & & & & & & \\
$(2)$ & 24.5 & & & & & & & \\
$(3)$ & 23.1 & & & & & & & \\
$(4)$ & 23.1 & 23.1 & 23.1 & 23.1 & 23.1 & 23.1 & 23.1 & 23.1 \\
$(5)$ & 106.0 & 107.4 & 107.0 & 107.2 & 104.3 & 103.5 & 104.8 & 104.3 \\
& & & & & & & & \\
\hline$(6)$ & 106.0 & & & & & & & \\
$(7)$ & 24.1 & & & & & & & \\
$(8)$ & 22.7 & & & & & & & \\
$(9)$ & 22.7 & 22.7 & 22.7 & 22.7 & 22.7 & 22.7 & 22.7 & 22.7 \\
$(10)$ & 24.1 & 24.4 & 24.3 & 24.3 & 23.7 & 23.5 & 23.8 & 23.7 \\
$(11)$ & 57.5 & 58.2 & 57.9 & 58.1 & 56.6 & 56.1 & 56.8 & 56.6 \\
\hline
\end{tabular}

- Total hours, home hours and leisure - Approach (2). We, first, need a series for total disposable time. From the time use we have the total time in 1998 which is: $H(098)+$ $L(098)=106.0$.

- Step 1: Assume that the total weekly time remains constant during the period from 1998 until 2005. See row (1):

- Step 2: Compute the share of weekly home hours in total weekly hours for 1998. See rows (2) [total weekly time in hours], (3) [weekly home hours], (4) share of weekly home hours in total time.

- Step 3: Assume that this share is constant during the period from 1998 to 2005 . See row (5).

- Step 4: Compute weekly home hours by multiplying the total weekly time by the share of home hours. See row (6). 
- Step 5: Compute leisure by subtracting market hours and home hours from the total weekly time. See row (7).

Table 18: Extrapolation of total time, home hours and leisure, Approach 2

\begin{tabular}{lrlllllll}
\hline year & 1998 & 1999 & 2000 & 2001 & 2002 & 2003 & 2004 & 2005 \\
\hline & & & & & & & & \\
(1) & 106.0 & 106.0 & 106.0 & 106.0 & 106.0 & 106.0 & 106.0 & 106.0 \\
(2) & 106.0 & & & & & & & \\
(3) & 24.1 & & & & & & & \\
(4) & 22.7 & & & & & & & \\
(5) & 22.7 & 22.7 & 22.7 & 22.7 & 22.7 & 22.7 & 22.7 & 22.7 \\
(6) & 24.1 & 24.1 & 24.1 & 24.1 & 24.1 & 24.1 & 24.1 & 24.1 \\
(7) & 57.5 & 57.2 & 57.3 & 57.2 & 57.9 & 58.1 & 57.8 & 57.9 \\
\hline
\end{tabular}

- Total hours, home hours and leisure - Approach (3). We, first, need a series for total disposable time. From the time use we have the total time in 1998 which is: $H(098)+$ $L(098)=106.0$.

- Step 1: Assume that the total weekly time remains constant during the period from 1998 until 2005. See row (1):

- Step 2: Compute the share of weekly home hours in weekly non-market hours for 1998. See rows (2) [weekly non-market time in hours], (3) [weekly home hours], (4) share of weekly home hours in non-market time.

- Step 3: Assume that this share is constant during the period from 1998 to 2005. See row (5).

- Step 4: Compute weekly home hours by multiplying the weekly non-market time by the share of home hours in non-market time. See row (6).

- Step 5: Compute leisure by subtracting market hours and home hours from the total weekly time. See row (7).

- Résumé: The differences between the three approaches are fairly small. 
Table 19: Extrapolation of total time, home hours and leisure, Approach 3

\begin{tabular}{lrlllllll}
\hline & 1998 & 1999 & 2000 & 2001 & 2002 & 2003 & 2004 & 2005 \\
\hline & & & & & & & & \\
(1) & 106.0 & 106.0 & 106.0 & 106.0 & 106.0 & 106.0 & 106.0 & 106.0 \\
$(2)$ & 81.5 & & & & & & & \\
$(3)$ & 24.1 & & & & & & & \\
$(4)$ & 29.5 & & & & & & & \\
$(5)$ & 29.5 & 29.5 & 29.5 & 29.5 & 29.5 & 29.5 & 29.5 & 29.5 \\
(6) & 24.1 & 24.0 & 24.0 & 24.0 & 24.2 & 24.2 & 24.1 & 24.2 \\
(7) & 57.5 & 57.3 & 57.3 & 57.3 & 57.8 & 57.9 & 57.7 & 57.8 \\
\hline
\end{tabular}

\section{Appendix A.3: Ramey versus Herrendorf-Duernecker cate- gories of home production}

The purpose of this part of the appendix is to clarify why the estimates of the average weekly home production time for the U.S. differ between our 2014 paper "On the Allocation of Time" and Valerie Ramey's 2009 paper "Time Spent in Home Production in the Twentieth-Century United States: New Estimates from Old Data".

Table 20: Average weekly hours of home work in the U.S.

\begin{tabular}{|c|c|c|c|c|c|c|c|c|c|}
\hline & & Age & Source & Categories & 1965 & 1975 & 1985 & 1995 & 2005 \\
\hline 1 & Ramey & $18-64$ & AHTUS & & 26.5 & 22.5 & 21.3 & 22.3 & 23.2 \\
\hline 2 & $\mathrm{D}-\mathrm{H}$ & $15-64$ & MTUS & 41 activities & 20.6 & 20.0 & 19.2 & 20.2 & 20.4 \\
\hline 3 & $\mathrm{D}-\mathrm{H}$ & $18-64$ & MTUS & 41 activities & 22.4 & 21.2 & 20.3 & 20.9 & 21.9 \\
\hline 4 & D-H & $18-64$ & MTUS & 69 activities - our categories & 27.4 & 23.7 & 23.0 & 23.8 & 24.7 \\
\hline 5 & $\mathrm{D}-\mathrm{H}$ & $18-64$ & MTUS & 69 activities - Ramey's categories & 26.8 & 22.9 & 21.8 & 22.4 & 23.5 \\
\hline
\end{tabular}

\section{Data sources}

Ramey uses The American Heritage Time Use Study (AHTUS) whereas we use The Multinational Time Use Surveys (MTUS), whereas we use the Multinational Time Use Surveys (MTUS), which is a repository that contains a large number of harmonized time use surveys for different countries and years. We use MTUS because its data is comparable across countries and time. While ATUS and MTUS are fairly close for the U.S., there are some differences and 
one should not expect Ramey's numbers to be exactly equal to our numbers even if we both follow exactly the same steps.

\section{Age groups}

Ramey considers the sample of individuals with age between 18 and 64 years. In contrast, we consider the individuals between 15 and 64 years of age, which is the standard definition of the working-age population. The third row in Table 20 shows our series computed for individuals with age between 18 and 64 years. The level of home hours is higher than in our original series and home hours now decline somewhat at the beginning of the time period.

\section{Categorization of activities}

MTUS has classification systems with 41 and 69 activities. Since the classification with 69 activities is not available for the 1965 and 1975 surveys for France, we use 41 activities for all countries and years. This ensures the cross-country comparability of our estimates of home production time.

Table 21: Home production activities in the MTUS classification system

\begin{tabular}{lll}
\hline 41 activities & 69 activities - D-H categories & 69 activities - Ramey's categories \\
\hline \multirow{3}{*}{$\begin{array}{l}\text { Cook, wash up } \\
\text { Housework }\end{array}$} & Food preparation, cooking & Food preparation, cooking \\
Odd jobs & Set table, wash/put away dishes & Set table, wash/put away dishes \\
Maintenance of home or car & Cleaning & Cleaning \\
Household management & Home/vehicle maintenance/improvement & Laundry, ironing, clothing repair \\
Pet care & Other domestic work & Home/vehicle maintenance/improvement \\
Gardening & Purchase goods & Other domestic work \\
Shopping & Purchase personal care services & Purchase goods \\
Child care & Purchase other services & \\
Adult care & Pet care (other than walk dog) & Purchase other services \\
& Physical or medical child care & Pet care (other than walk dog) \\
& Teach child a skill, help with homework & Physical or medical child care \\
& Read to, talk or play with child & Teach child a skill, help with homework \\
& Supervise, accompany, other child care & Supervise, accompany, other child care \\
& Adult care & Adult care \\
& Child/adult care-related travel & \\
Travel for shopping, personal/household care & Travel for shopping, personal/household care \\
\hline
\end{tabular}

Since the MTUS data for the U.S. has both activity classifications, we can check by how much our numbers change if we apply the classification with 69 activities instead of that with 41 activities. The fourth row in the table has the results. Three remarks are in order. First, the constancy of home hours between 1975 and 2005 is largely preserved. Second, the drop in home hours between 1965 and 1975 is now more pronounced than before and the magnitude of the change is close to what Ramey finds (14\% in our data versus $15 \%$ in Ramey). Third, 
the level of home hours is higher than before. The last point is due to the fact that using the finer classification allows us to be more accurate when we classify home production activities. As a result, several activities are now part of home production but were previously included in leisure, market production or personal care time. This applies for instance to several activities related to travel (for instance, child/adult care-related travel and travel for shopping, or household care). The second and the third column in Table 21 show, for both activity classifications, all activities that our definition includes in home production

\section{Ramey's categorization of activities}

Ramey excluded a number of activities from home production that are arguably part of home production. The reason for doing this was that the pre-1965 time use data that she utilizes do not report these activities, so by excluding them she ensured the consistency of her categorization over time. The last row in Table 20 below shows our estimates for home hours if we exclude the same activities from our definition of home production as Ramey did. These activities include for instance "purchasing personal care services" or "adult care travel". The third column in Table 21 shows the remaining home production activities included in our definition. As expected, the level of home production time drops further. More importantly, the last series is very close to Ramey's series indeed.

\section{Appendix A.4: Calculation of home capital and labor produc- tivity}

\section{Home capital and labor productivity in France}

\section{Home capital, Version 1}

Step 1: Take the data from the OECD on final consumption expenditures (in national currency and current prices) on the following goods categories ${ }^{24}$ : P31CP051: Furniture and furnishings, carpets and other floor coverings, P31CP052: Household textiles, P31CP053: Household appliances, P31CP054: Glassware, tableware and household utensils, P31CP055: Tools and equipment for house and garden, P31CP061: Medical products, appliances and equipment, P31CP071: Purchase of vehicles, P31CP082: Telephone and telefax equipment, P31CP091: Audio-visual, photographic and information processing equipment, P31CP092: Other major durables for recreation and culture, P31CP093: Other recreational items and equipment, gardens and pets, P31CP095: Newspapers, books and stationery.

\footnotetext{
${ }^{24}$ The label of the dataset is Dataset: 5. Final consumption expenditure of households.
} 
There is an (almost) one-to-one mapping between these categories and those that the BEA includes in its variable Consumer Durable Goods. The availability of the OECD expenditures data differs across countries. For instance, for France, the data are available from 1959 onwards, whereas the series for Spain starts only in 2000. In our baseline scenario, we do not include housing into our measure of the capital stock. Only a certain fraction of the housing stock is used for household production (e.g. the kitchen), whereas the rest is used for different purposes. It is hard to quantify this fraction which is why we disregarded it at this point. We will consider alternative definitions of household capital in the future. Most likely, we will consider a broad and a narrow definition in addition to the baseline scenario. The broad definition includes consumer durables (as in the baseline) and housing whereas the narrow definition includes assets whose use is unambiguously linked to household production (such as household appliances).

Step 2: Use the perpetual investment method (PIM) to compute the stock for each asset category. Start by setting the initial stock of category $i, K(59)^{i}$ equal to initial investment $I(59)^{i}$. Then, use the standard formula to compute the series for $K(t)_{t=60}^{10}$ in a recursive manner: $K(t)^{i}=\left(1-\delta^{i}\right) K_{t-1}^{i}+I(t)^{i}$. The depreciation rate is asset-specific and constant over time. The value of $\delta^{i}$ is taken from the BEA and corresponds to the 1925-2012 average depreciation rate for each of the asset categories (computed as Depreciation $\left.(t)^{i} / \operatorname{Stock}(t)^{i}\right)$. Taking the 1960-2010 average or the 1970-2005 average instead of the 1925-2012 average makes only a very small difference. The depreciation rates for the different asset classes range from $14 \%$ to $31 \%$. The high values of $\delta^{i}$ guarantee that the capital stock computed via the PIM converges to the "true" stock relatively quickly. We compute the current-cost capital stock. This requires to, first, transform past investments into current-price investment. That is, to compute period- $t$ capital, we express the investment of periods $t-1, t-2, \ldots$ in prices of period $t$ and, then, apply the PIM.

Step 3: Compute the total capital stock for each period by aggregating up the individual stocks: $K(t)^{C D}=\sum_{i} K(t)^{i}$.

\section{Home capital, Version 2}

Step 1: Take the data from the OECD on final consumption expenditures (in national currency and current prices) on P311B: Durable goods. The OECD categorizes consumer expenditures into four different classes: Durable goods, Semi-Durable goods, Non-Durable goods, Services. It is not visible for an OECD-outsider how this categorization is done, i.e. which expenditure categories are included in each of these four groups. However, it is certain that Durable goods is a subset of what has been considered as Durable Goods in the Version 1 above (because the sum of expenditures is larger then the reported expenditures on Durable goods). 
Step 2: Use the PIM to compute the stock. The depreciation rate is taken from the BEA and it is equal to the 1925-2012 average depreciation rate for Consumer Durable Goods.

The difference between the Version 1 total stock and the Version 2 stock is sizable (and equal to around 35\%) but very stable over time. To illustrate: the stock increases between 1980 to 2010 by a factor 4.9 for Version 1 and by a factor of 4.8 for Version 2 (over the period 1990 to 2010 the numbers are 1.88 and 1.81 ).

\section{Labor Productivity in Home Production}

Step 1: Compute current-price value added. Value added is the sum of two components and computed as follows:

$$
\mathrm{VA}=(r+\delta) * \text { capital input }+w * \text { labor input }
$$

Now, let's talk about the computation of the individual components.

1. Capital input ... is equal to the nominal stock of consumer durables and it is computed as described above. In the baseline scenario, we use the procedure labeled as Version 1. Data source: see above.

2. $\delta$ is the depreciation rate. We do not use some aggregate depreciation rate and multiply it with the aggregate home capital stock. To be more accurate, we compute instead the aggregate home capital depreciation by using the capital stocks for each asset category (as described above) together with the asset-specific depreciation rates. I.e. $\delta * K(t)=$ $\sum_{i} \delta^{i} K(t)^{i}$. Data source: see above.

3. $\mathbf{r}$ is the gross return on consumer durables. Ideally we would like to have information on the rate of return of individual financial asset holdings. If we had this return, we could invoke an arbitrage argument and apply the same rate of return for household capital (that is: when the agent has two investment opportunities - household capital and financial assets - then the rate of return has to be equalized in equilibrium). We do not have this information for most OECD countries, so we use the nominal yield on the respective country's 10-year government bonds as a proxy. One way to improve this approximation would go as follows: we have the data on the rate of return on financial assets for a short period of time (2000-2010). For this period, we can compute the spread between this return and government 10-year bond returns. Then, we make the assumption that this spread is constant over time and add it to the observed government bond return to get the return on financial assets. NOTE: this modification will affect - if anything - only the 
level of home value added but not the change over time because of the constant spread. Data source: FRED, Saint Louis Fed

4. Labor input ... is the annual aggregate amount of time (measured in hours) spent on household work by individuals aged between 15-64 years. This variable is computed as the product of the annual individual hours of household work and the total population aged between 15 and 64 years. We do not capture the household work done by individuals younger than 15 and older than 64 years (also not for the U.S.). There is limited or no time use data for these age groups and that is why we do not consider them.

The annual individual hours of household work are computed as the weekly individual hours of household work times 52. The weekly individual hours of household work are computed from the Multinational Time Use Study (MTUS).

Data sources: MTUS (individual time use data), OECD (population aged 15-64 years).

5. $\mathbf{w}$ is the return on the labor input. To compute $w$, we use data on the hourly compensation of private household workers, i.e. people who are directly employed by households to do household work. The main assumption is that the marginal product of these household workers is the same as the marginal product of a non-household worker who is doing household work. We use data from the EU-KLEMS on (i) total annual hours worked by private $\mathrm{HH}$ workers and (ii) the total labor compensation of private $\mathrm{HH}$ workers. We divide the latter by the former to obtain the hourly compensation which is our measure of w.

Step 2: Compute constant-price home value added. The central question here is, which price index to use to convert current-price into constant-price value added. We explore two different approaches: (a) the price index of value added of the household sector, (b) the price index of private consumption expenditures on goods and services which have a home-produced substitute. The key disadvantage of the first approach is that the main component of household sector value added is housing services (rents and owner-occupied housing), hence the price index would give us the price of housing which is somewhat unrelated to what we are trying to capture by household production (also, we do not consider housing capital as input in household production. Approach (b) is not ideal either because it a final expenditure price and not a value added price. The idea behind (b) is as follows: all home-produced goods and services have a market-produced substitute. That is, all home production could be outsourced to the market. Hence, when we look at the market price of goods and services which could be produced by the household, then we have an approximation of the price of the household's actual output. This consideration abstracts from issues regarding the composition of household output. That 
is, it assumes that the output bundle of the home sector is comparable to the composition of home-substitutes produced in the market.

In the baseline case, we chose (b) and compute the price index as follows. We take the data provided by the OECD on final consumption expenditures of households on Food and nonalcoholic beverages, Clothing, Maintenance and repair of the dwelling, Goods and services for routine household mainte.ce, Out-patient services, Hospital services, Operation of personal transport equipment, Transport services, Restaurants and hotels, Personal care ${ }^{25}$. This is our list of market-produced goods and services which have a home-produced substitute. To compute a single price index, we divide the sum of current price expenditures by the sum of constant price expenditures (the constant-price series in NOT chained - hence we can do the summation). The base year of this index is 2005 .

Finally, we divide the value of nominal value added by the price index to obtain the constant price value added.

Step 3: PPP-adjustment. To make the series comparable across countries, we do a PPPadjustment of the constant price series. Again, the question is, what PPP factor to use? Obviously, there is no data on PPP for home value added, so we have to come up with a proxy. The OECD provides data on PPPs for a large class of final expenditure categories for the year 2005. We proceed as in Step 2 above and construct a composite PPP using the PPPs for those expenditure categories which have a home produced substitute. In particular, we compute the aggregate PPP factor as the expenditure-weighted average of the PPPs of the following categories: Food and non-alcoholic beverages, Clothing and footwear, Housing, water, electricity, gas and other fuels, Household furnishings, equipment and maintenance, Health, Transport, Restaurants and hotels.

Finally, we divide the constant price series of home value added by the PPP factor to obtain the adjusted series

Step 4: Labor productivity. In the last step, we divide the constant price, constant PPP series of home value added by the annual aggregate hours of household work (mentioned above in Step 1) to obtain labor productivity.

\section{U.S.}

Step 1: Compute current-price value added. This is done in the same way as above. I.e. value added is the sum of two components and computed as follows:$$
\mathrm{VA}=(r+\delta) * \text { capital input }+w * \text { labor input }
$$

${ }^{25}$ The dataset is called Dataset: 5. Final consumption expenditure of households.
} 
1. The capital input is equal to the nominal stock of consumer durables. There's no need to do the PIM because the BEA provides data for the nominal stock of consumer durables (BEA Table 8.1)

2. The depreciation is taken from the BEA Table 1.3.

3. The gross return on consumer durables $\mathbf{r}$ is set equal to the return on financial assets. This return is computed as the Personal income receipts on assets (BEA Table 2.1) divided by total financial assets (Flow of Funds) net of equity in noncorporate business (Flow of funds).

4. As above, the labor input is the annual aggregate amount of time (measured in hours) spent on household work by individuals aged between 15-64 years. This variable is computed in the same way as above.

5. The return on the labor input $\mathbf{w}$ is computed as above as the Compensation of private $H H$ workers (BEA 6.2) divided by the FTE private HH workers thousands (BEA 6.5).

Step 2: Compute constant-price home value added. We use the same price index as above and it is computed using the following final expenditure categories: Food and nonalcoholic beverages purchased for off-premises consumption, Food produced and consumed on farms, Garments, Household supplies, Outpatient services, Hospital and nursing home services, Motor vehicle services, Ground transportation, Purchased meals and beverages, Nursery, elementary, and secondary schools, Personal care and clothing services, Social services and religious activities, Household maintenance. The data is taken from BEA tables 2.4.3 and 2.4.5. 


\section{Appendix B: First-order Conditions for an Interior Solution to the Household Problem}

The Lagrangian to the household problem is as follows:

$$
\begin{aligned}
\mathcal{L} & =\sum_{t=0}^{\infty} \beta^{t}\left\{\alpha_{u} \log (C(t)-\bar{C})+\left(1-\alpha_{u}\right) \log (L(t))+\eta_{c}(t)\left(\left[\alpha_{c} C_{m}(t)^{\sigma_{c}}+\left(1-\alpha_{c}\right) C_{h}(t)^{\sigma_{c}}\right]^{\frac{1}{\sigma_{c}}}-C(t)\right)\right. \\
& +\eta_{h}(t)\left(\left[\alpha_{h} K_{h}(t)^{\sigma_{h}}+\left(1-\alpha_{h}\right)\left(A_{h}(t) H_{h}(t)\right)^{\sigma_{h}}\right]^{\frac{1}{\sigma_{h}}}-C_{h}(t)\right) \\
& +\lambda(t)\left[\left[1-\tau_{w}(t)\right] w(t) H_{m}(t)+\left[1-\tau_{r}(t)\right] r(t) K_{m}(t)+T(t)-C_{m}(t)-p_{h}(t) X_{h}(t)-\left[1+\tau_{x}(t)\right] p_{m}(t) X_{m}(t)\right] \\
& +\phi_{m}(t)\left[\left(1-\delta_{m}\right) K_{m}(t)+X_{m}(t)-K_{m}(t+1)\right]+\phi_{h}(t)\left[\left(1-\delta_{h}\right) K_{h}(t)+X_{h}(t)-K_{h}(t+1)\right] \\
& \left.+\mu(t)\left[1-L(t)-H_{m}(t)-H_{h}(t)\right]\right\}
\end{aligned}
$$

The first-order conditions to household's problem stated in the body of the paper are given by (8)-(9) and

$$
\begin{aligned}
\frac{\partial \mathcal{L}}{\partial C(t)}: & 0=\frac{\alpha_{u}}{C(t)-\bar{C}}-\eta_{c}(t) \\
\frac{\partial \mathcal{L}}{\partial L(t)}: & 0=\frac{1-\alpha_{u}}{L(t)}-\mu(t) \\
\frac{\partial \mathcal{L}}{\partial C_{m}(t)}: \quad & 0=\eta_{c}(t) C(t)^{1-\sigma_{c}} \alpha_{c} C_{m}(t)^{\sigma_{c}-1}-\lambda(t) \\
\frac{\partial \mathcal{L}}{\partial C_{h}(t)}: & 0=\eta_{c}(t) C(t)^{1-\sigma_{c}}\left(1-\alpha_{c}\right) C_{h}(t)^{\sigma_{c}-1}-\eta_{h}(t) \\
\frac{\partial \mathcal{L}}{\partial H_{m}(t)}: & 0=\lambda(t)\left[1-\tau_{w}(t)\right] w(t)-\mu(t) \\
\frac{\partial \mathcal{L}}{\partial H_{h}(t)}: & 0=\eta_{h}(t) C_{h}(t)^{1-\sigma_{h}}\left(1-\alpha_{h}\right) A_{h}(t)^{\sigma_{h}} H_{h}(t)^{\sigma_{h}-1}-\mu(t) \\
\frac{\partial \mathcal{L}}{\partial X_{m}(t)}: & 0=-\lambda(t)\left[1+\tau_{x}(t)\right] p_{m}(t)+\phi_{m}(t) \\
\frac{\partial \mathcal{L}}{\partial X_{h}(t)}: & 0=-\lambda(t) p_{h}(t)+\phi_{h}(t) \\
\frac{\partial \mathcal{L}}{\partial K_{m}(t+1)}: & 0=-\phi_{m}(t)+\beta\left(\lambda(t+1)\left\{\left[1-\tau_{r}(t+1)\right] r(t+1)+\tau_{x}(t+1) p_{m}(t+1) \delta_{m}\right\}+\phi_{m}(t+1)\left(1-\delta_{m}\right)\right) \\
\frac{\partial \mathcal{L}}{\partial K_{h}(t+1)}: & 0=-\phi_{h}(t)+\beta\left(\eta_{h}(t+1) C_{h}(t+1)^{1-\sigma_{h}} \alpha_{h} K_{h}(t+1)^{\sigma_{h}-1}+\phi_{h}(t+1)\left(1-\delta_{h}\right)\right)
\end{aligned}
$$




\section{Appendix C: Derivations for Section 5.2}

Without capital, the household problem simplifies to:

$\max \alpha_{u} \log (C-\bar{C})+\left(1-\alpha_{u}\right) \log (L)$

$$
\text { s.t. } C=\left(\alpha_{c} C_{m}^{\sigma_{c}}+\left(1-\alpha_{c}\right) C_{h}^{\sigma_{c}}\right)^{\frac{1}{\sigma_{c}}}, \quad C_{m}=\left(1-\tau_{w}\right) w H_{m}+T, \quad 1=L+H_{m}+H_{h}, \quad C_{h}=A_{h} H_{h}
$$

The Lagrangian is:

$$
\begin{aligned}
\mathcal{L} & =\alpha_{u} \log (C-\bar{C})+\left(1-\alpha_{u}\right) \log (L)+\eta_{c}\left[C-\left(\alpha_{c} C_{m}^{\sigma_{c}}+\left(1-\alpha_{c}\right) C_{h}^{\sigma_{c}}\right)^{\frac{1}{\sigma_{c}}}\right] \\
& +\eta_{h}\left[A_{h} H_{h}-C_{h}\right]+\lambda\left[\left(1-\tau_{w}\right) w H_{m}+T-C_{m}\right]+\mu\left[1-L-H_{m}-H_{h}\right]
\end{aligned}
$$

The first-order conditions are:

$$
\begin{array}{ll}
\frac{\partial \mathcal{L}}{\partial C}: & \frac{\alpha_{u}}{C-\bar{C}}=\eta_{c} \\
\frac{\partial \mathcal{L}}{\partial L}: & \frac{1-\alpha_{u}}{L}=\mu \\
\frac{\partial \mathcal{L}}{\partial C_{m}}: & \eta_{c} C^{1-\sigma_{c}} \alpha_{c} C_{m}^{\sigma_{c}-1}=\lambda \\
\frac{\partial \mathcal{L}}{\partial C_{h}}: & \eta_{c} C^{1-\sigma_{c}}\left(1-\alpha_{c}\right) C_{h}^{\sigma_{c}-1}=\eta_{h} \\
\frac{\partial \mathcal{L}}{\partial H_{m}}: & \lambda\left(1-\tau_{w}\right) w=\mu \\
\frac{\partial \mathcal{L}}{\partial H_{h}}: & \mu=\eta_{h} A_{h}
\end{array}
$$

To derive (18), we rewrite (22)-(23) as:

$$
\begin{aligned}
& \eta_{c} C^{\frac{1}{\epsilon_{c}}} \alpha_{c} C_{m}^{-\frac{1}{\epsilon_{c}}}=\lambda \\
& \eta_{c} C^{\frac{1}{\epsilon_{c}}}\left(1-\alpha_{c}\right) C_{h}^{-\frac{1}{\epsilon_{c}}}=\frac{\mu}{A_{h}}=\lambda \frac{\left(1-\tau_{w}\right) w}{A_{h}}=\lambda p_{h}
\end{aligned}
$$

Next, we raise each of these equations to the power $1-\epsilon_{c}$ and rearrange:

$$
\begin{aligned}
& \eta_{c}^{1-\epsilon_{c}} C^{\frac{1-\epsilon_{c}}{\epsilon_{c}}} \alpha_{c} C_{m}^{-\frac{1-\epsilon_{c}}{\epsilon_{c}}}=\lambda^{1-\epsilon_{c}} \alpha_{c}^{\epsilon_{c}} \\
& \eta_{c}^{1-\epsilon_{c}} C^{\frac{1-\epsilon_{c}}{\epsilon_{c}}}\left(1-\alpha_{c}\right) C_{h}^{-\frac{1-\epsilon_{c}}{\epsilon_{c}}}=\lambda^{1-\epsilon_{c}}\left(1-\alpha_{c}\right)^{\epsilon_{c}} p_{h}^{1-\epsilon_{c}}
\end{aligned}
$$


Adding these two equations and raising the result to the power of $1 /\left(1-\epsilon_{c}\right)$ gives us:

$$
\eta_{c}=\lambda P
$$

Using this equations and the first-order conditions from above, we obtain a consolidated firstorder condition for the allocation of $C$ and $L$ :

$$
\left(1-\alpha_{u}\right) P(C-\bar{C})=\alpha_{u}\left(1-\tau_{w}\right) w L
$$

In order to obtain the closed-form solution (18), we need to bring in the budget constraints of the government and the households. Combining them gives:

$$
w H_{m}=C_{m}
$$

Adding $p_{h} C_{h}$ on each side and using that $p_{h} C_{h}=\left(1-\tau_{w}\right) w H_{h}$, we get:

$$
w(1-L)-\tau_{w} w H_{h}=C_{m}+p_{h} C_{h}
$$

The next step is to show that:

$$
C_{m}+p_{h} C_{h}=P C
$$

We begin by rewriting (26)-(27) to:

$$
\begin{aligned}
& C^{\frac{1}{\epsilon_{c}}} \alpha_{c} C_{m}^{\frac{\epsilon_{c}-1}{\epsilon_{c}}}=\frac{\lambda}{\eta_{c}} C_{m} \\
& C^{\frac{1}{\epsilon_{c}}}\left(1-\alpha_{c}\right) C_{h}^{\frac{\epsilon_{c}-1}{\epsilon_{c}}}=\frac{\lambda}{\eta_{c}} p_{h} C_{h}
\end{aligned}
$$

Adding these two equations and using (17) gives:

$$
C^{\frac{1}{\epsilon_{c}}} C^{\frac{\epsilon_{c}-1}{\epsilon_{c}}} P=C P=C_{m}+p_{h} C_{h}
$$

Combining (29)-(30), we find:

$$
w(1-L)-\tau_{w} w H_{h}=P C
$$

Equations (28) and (31) imply the closed-form solution (18) for leisure that we used in the main text. 